ARTICLE

\title{
Enhancing digestibility and ethanol yield of Populus wood via expression of an engineered monolignol 4-O-methyltransferase
}

Yuanheng Cai ${ }^{1, \star}$, Kewei Zhang ${ }^{1, \star, \dagger}$, Hoon Kim²${ }^{2}$, Guichuan Hou ${ }^{3}$, Xuebin Zhang ${ }^{1}$, Huijun Yang ${ }^{1, \dagger}$, Huan Feng ${ }^{1,4}$, Lisa Miller ${ }^{5}$, John Ralph ${ }^{2} \&$ Chang-Jun Liu ${ }^{1}$

Producing cellulosic biofuels and bio-based chemicals from woody biomass is impeded by the presence of lignin polymer in the plant cell wall. Manipulating the monolignol biosynthetic pathway offers a promising approach to improved processability, but often impairs plant growth and development. Here, we show that expressing an engineered 4-O-methyltransferase that chemically modifies the phenolic moiety of lignin monomeric precursors, thus preventing their incorporation into the lignin polymer, substantially alters hybrid aspens' lignin content and structure. Woody biomass derived from the transgenic aspens shows a $62 \%$ increase in the release of simple sugars and up to a $49 \%$ increase in the yield of ethanol when the woody biomass is subjected to enzymatic digestion and yeast-mediated fermentation. Moreover, the cell wall structural changes do not affect growth and biomass production of the trees. Our study provides a useful strategy for tailoring woody biomass for bio-based applications.

\footnotetext{
${ }^{1}$ Biology Department, Brookhaven National Laboratory, Upton, New York 11973, USA. ${ }^{2}$ Department of Biochemistry, and the DOE Great Lakes Bioenergy Research Center, The Wisconsin Energy Institute, University of Wisconsin, Madison, Wisconsin 53726, USA. ${ }^{3}$ Dewel Microscopy Facility, Appalachian State University, Boone, North Carolina 28608-2027, USA. ${ }^{4}$ Department of Earth and Environmental Studies, Montclair State University, Montclair, New Jersey 07043, USA. ${ }^{5}$ National Synchrotron Light Source, Brookhaven National Laboratory, Upton, New York 11973, USA. * These authors contributed equally to this work. † Present addresses: College of Chemistry and Life Sciences, Zhejiang Normal University, Zhejiang 321004, China (K.Z.); Department of Plant Pathology and Plant-Microbe Biology, Cornell University, Ithaca, New York 14853-4203, USA (H.Y.). Correspondence and requests for materials should be addressed to C.-J.L. (email: cliu@bnl.gov).
} 
W ood is one of the world's most abundant natural materials. It is widely used in pulp and paper manufacturing and recently has been considered a promising source of simple sugars for industrial bio-based products and advanced biofuels ${ }^{1}$. Wood is the secondary xylem of vascular plants, consisting of a compound middle lamella and secondary wall layers composed of a cellulose/hemicellulose network, and impregnated with lignin. In the wood of Populus spp., these polymers occur in the approximate proportions of $45 \%$ cellulose, $25 \%$ hemicelluloses and $20 \% \operatorname{lignin}^{2}$. Lignin in the wood forms a hydrophobic barrier hindering the access of digestive enzymes to polysaccharides and decreasing their activity; therefore, it is a significant limiting factor in converting woody biomass to fermentable sugars in processes towards biofuels ${ }^{1}$. Lignins are complex and heterogeneous polymers of 4-hydroxyphenylpropanoid units ${ }^{3}$. They are derived from the oxidative radical coupling of three typical building blocks (that is, the monolignols), p-coumaryl, coniferyl and sinapyl alcohols (Fig. 1a). After their incorporation into the growing lignin polymer, these hydroxycinnamyl alcohols correspondingly produce $p$-hydroxyphenyl $(\mathrm{H})$, guaiacyl $(\mathrm{G})$ and syringyl (S) subunits. The amount and composition of lignin varies among taxa, cell types and the individual layers of the cell walls. In general, the S/G ratio dictates the degree of lignin condensation and reactivity by supporting different types of subunit linkages. A higher G-unit content creates more condensed lignin that is composed of a greater portion of biphenyl, phenylcoumaran and other carbon-carbon linked units as their 5-position on the aromatic ring is available for radical coupling reactions. S-units, in contrast, are more commonly linked through ether bonds at the available 4-hydroxy position of the growing lignin polymer yielding more linear and chemically relatively labile polymers ${ }^{3}$. For several decades, considerable effort has been expended in tailoring monolignol biosynthesis to control lignin content and/or composition. Several studies have successfully demonstrated that reducing lignin content or modifying its structure in plants could translate into improved saccharification efficiency, and thus, lead to reduced biomass conversion costs $^{4-7}$. A few studies also reported that manipulating monolignol biosynthetic genes such as caffeic acid $O$-methyltransferase (COMT), and 4-coumarateCoA ligase (4CL) in, for example, swtichgrass (Panicum virgatum) or ryegrass (Lolium pernne), appeared to have no negative effect on crop's agronomic performance and/or biomass yield $^{8-10}$. However, on the other hand, many investigations of different plant species show that the growth and development of the engineered plants is often compromised by the simple disruption of the monolignol biosynthetic pathway, and/or by a dramatic reduction of the content of lignin in the cell wall ${ }^{11}$. This is particularly evident in the manipulation of hydroxycinnamoylCoA: shikimate hydroxycinnamoyl transferase (HCT) gene in alfalfa ${ }^{12}$, cinnamate 4-hydroxylase $(C 4 H)$, coumaroyl $3^{\prime}$-hydroxylase $\left(C 3^{\prime} H\right)$, and cinnamoyl-coa reductase $(C C R)$ genes in Arabidopsis, alfalfa, and hybrid poplars $6,13-15$. Even though down-regulation of $4 C L$ did not affect biomass production of swtichgrass, the silencing of this gene in pine ${ }^{16}$ and poplar caused obviously stunted plant growth ${ }^{77,18}$. Similarly, COMT-deficient brown midrib mutants of maize $(\mathrm{bm} 3)$ and sorghum (bmr12), and COMT-downregulated sugarcane exhibited a biomass yield reduction ${ }^{19-21}$. Therefore, it is desirable to further explore a more effective strategy to modulate lignin synthesis and structure, thus improving the efficiency of the bioconversion of wood, while sustaining the plant growth and development.

Lignin polymerization commences with one-electron oxidation of the phenols of monolignols by oxidative enzymes, laccases and/or peroxidases, to yield activated radical intermediates.
The coupling of monolignol radicals with each other (for the initiation of lignin polymer) and, more importantly, with the growing polymer forms lignins ${ }^{3,22}$ (Fig. 1b). In this process, a free phenol (the unsubstituted 4-hydroxy group of a monolignol, and/or the free-phenolic end of the growing polymer), is essential for generating phenolic radicals to allow radical coupling that forms the different types of lignin inter-unit linkages ${ }^{3,23}$. Previously, we demonstrated that chemical modification, that is, the methylation of the 4-hydroxy group of a monolignol, prevents the participation of the monolignol derivative in the subsequent coupling process, thus disrupting lignin formation ${ }^{24}$. Based on this observation, we engineered a set of novel $O$-methyltransferase (OMT) variants using structure-guided iterative saturation mutagenesis. These OMT variants effectively catalyse the 4-O-methylation of monolignols, and are therefore termed monolignol 4-O-methyltransferases (MOMTs) ${ }^{24}$ (Fig. 1c). One of these variants, MOMT4, shows a slight catalytic preference for methylating sinapyl alcohol, the S-lignin precursor, in vitro ${ }^{25}$. To evaluate its potential effects on lignin synthesis in woody species, and its application in tailoring wood digestibility for biofuel production, in this study we express MOMT4 in hybrid aspen (Populus tremula $\times$ Populus alba), a fast growing Populus species. We demonstrate that the expression of MOMT4 in aspen markedly alters lignin structure, with more than a 50\% reduction of the labile S-units and about a fourfold increase in condensed lignin subunit cross-linkages by G-units. However, in contrast to our common perception, along with the increase of condensed lignin structures, the efficiency of the release of simple sugars from transgenic woods increases up to $62 \%$, and the ethanol yield from pretreated and non-treated transgenic woods rise by $>40 \%$ and $49 \%$, respectively, compared with those from their corresponding controls. Furthermore, the content and composition changes in lignin do not affect growth and fitness of the transgenic aspens in the greenhouse; the wood densities and the biomass yields are comparable to those of the controls. These data suggest that (1) lignin condensation itself is not a critical factor affecting the digestibility of the cell wall; (2) the developed strategy of etherifying lignin precursors by the engineered OMT represents a useful biotechnological solution for effectively tailoring the digestibility of Populus woody biomass and, (3) the created transgenic aspens are a promising advanced biomass feedstock for biofuel production.

\section{Results}

Alteration of lignin content and structure. MOMT4, one of engineered enzyme variants from the parent enzyme isoeugenol 4-O-methyltransferase ${ }^{26}$, possesses four amino acid substitutions in its active site, that is, T133L, E165I, F175I and H169F (ref. 25). Those substitutions confer a substantial catalytic efficiency of the enzyme to both coniferyl alcohol and sinapyl alcohol for p-hydroxyl methylation. Kinetically, MOMT4 slightly prefers sinapyl alcohol with a catalytic efficiency $\left(k_{\mathrm{cat}} / K_{\mathrm{m}}\right)$ of 3,999.3 $\left(\mathrm{M}^{-1} \mathrm{~s}^{-1}\right)$, and a binding affinity $\left(K_{\mathrm{m}}\right)$ of $68.1 \pm 11.1$ ( \pm indicates s.d., $n=3) \mu \mathrm{M}$ versus $2,738.7\left(\mathrm{M}^{-1} \mathrm{~s}^{-1}\right.$ ) and $192.6 \pm 24.5$ ( \pm indicates s.d., $n=3) \mu \mathrm{M}$ for coniferyl alcohol. We transferred the expression cassette of the MOMT4 gene, driven by the promoter of the bean phenylalanine ammonium lyase-2 (PAL2) gene that encodes the enzyme catalysing the first step of phenylpropanoid/lignin biosynthesis ${ }^{27}$, into hybrid aspen via Agrobacterium-mediated transformation (Fig. 2a). Bean PAL2 promoter has been demonstrated to be highly active in the early stage of vascular development at the inception of xylem differentiation, when it drives the glucuronidase reporter gene, and is heterologously 
expressed in tobacco ${ }^{28}$; its promoter property was well conserved, even expressing in gymnosperm species ${ }^{29}$. Furthermore, this promoter has been successfully adopted in driving the target genes to effectively disturb lignin biosynthesis in different plants ${ }^{14,25}$. After obtaining the independent primary transformants, $\sim 2$-month-old transgenic trees grown in a greenhouse were initially screened. Profiling the methanolic extracts from the plants revealed that two novel metabolites had accumulated in the leaves of the established transgenic lines (Supplementary Fig. 1a,b). After digestion of the leaf extract with $\beta$-glucosidase, we found that one metabolite we resolved was identical to the 4-O-methylated coniferyl alcohol, and the other one was identical to the 4-O-methylated sinapyl alcohol, based on their retention times and ultraviolet spectra, compared with the enzymatically synthesized authentic standards, as was their molecular mass assignment (detected by gas chromatography-mass spectrometry (GC-MS)) (Supplementary Fig. 1a-f). These data indicate that the engineered MOMT4 functions properly in the transgenic aspens, and can modify monolignols into the corresponding 4-O-methylated compounds; those methylated products most likely were further transformed to their glucoconjugates for detoxification and/or for the storage. The levels of the accumulated metabolites in the leaves of $\sim 2$-month-old trees were $\sim 2-3 \mu \mathrm{molg}^{-1}$ of the fresh weight of the leaves for the 4-O-methylated coniferyl alcohol, and $5-7 \mu \mathrm{mol} \mathrm{g}^{-1}$ fresh weigh for the 4-O-methylated sinapyl alcohol (Supplementary Fig. 1g). Interestingly, in the stems of $\sim 2$-month-old trees, only 4-O-methylated sinapyl alcohol was detected, and its accumulation level was much lower than that in the leaves at $\sim 0.12-0.2 \mu \mathrm{molg}^{-1}$ fresh weight, which probably reflects the limited storage capacity of xylem cells for the soluble phenolics. Based on the phenolic profiling and the preliminary quantification of the total lignin content of these generated transgenic lines, we selected four independent lines, covering the lowest- to the highest-level of metabolic changes, for our further detailed histochemical and chemical analyses on the composition of their cell walls. The conventional phloroglucinol-HCl stain that yields a violet-red colour indicative of total lignin revealed that the xylem tissues of MOMT4 transgenic aspens exhibited a slightly weaker (or nearly indiscernible change in) colour intensity than those of the control plants (Fig. 2b,c), suggesting a limited reduction of total lignin content in the wood; however, when we applied the Mäule stain (which stains syringyl units in lignin red), the colour intensity apparent on the cross-section of MOMT4 transgenic stem was undoubtedly fainter than that displayed in the control stem (Fig. 2d,e), indicating a substantial a<smiles>[R]c1cc(C=CCO)cc(P)c1O</smiles>

$\mathrm{R}_{1}=\mathrm{R}_{2}=\mathrm{H}, p$-Coumaryl alcohol $(\mathrm{H})$ $\mathrm{R}_{1}=\mathrm{H} \mathrm{R}_{2}=\mathrm{OMe}$, Coniferyl alcohol (G) $\mathrm{R}_{1}=\mathrm{R}_{2}=\mathrm{OMe}$, Sinapyl alcohol (S)
C<smiles>COc1cc(/C=C/CO)cc(P)c1O</smiles>

$\mathrm{R}=\mathrm{H}$, Coniferyl alcohol (G) $\mathrm{R}=\mathrm{OMe}$, Sinapyl alcohol (S)

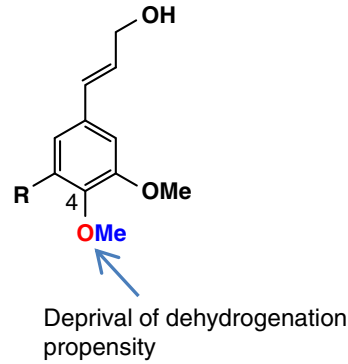
propensity b<smiles>COc1ccc(/C=C/CO)cc1O</smiles><smiles></smiles><smiles>COC1=CC(/C=C/CO)=CCC1=O</smiles><smiles>CCOc1ccc(/C=C/CO)cc1OC</smiles><smiles></smiles>

Cross-coupling or coupling to lignin

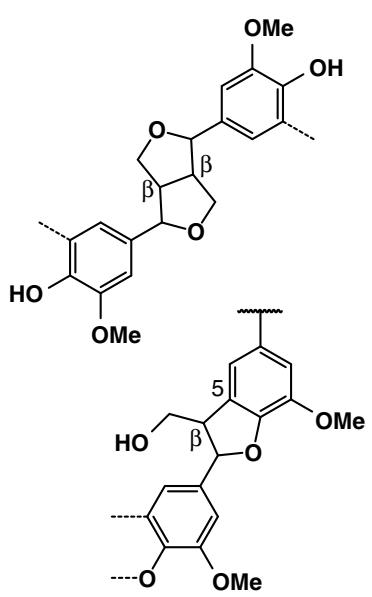<smiles>COc1ccc(C(O)C(CO)Oc2c(C)cc(C(C)C)cc2OC)cc1C(O)C(CO)Oc1c(OC)cc(C(C)C)cc1Sc1cc(C(C)C)cc(OC)c1OC(O)C(C)C</smiles>

Figure 1 | Illustration of MOMT4-medidated depression on lignin polymerization. (a) The conventional monolignol structures. (b) Scheme for monolignol oxidative dehydrogenation and polymerization processes. (c) The reaction catalysed by the engineered monolignol 4-O-methyltransferase, which deprives the propensity of the modified lignin precursors for further polymerization. 
reduction of S-type lignin subunits in the cell walls of MOMT4 transgenic lines. Consistent with the histochemical observation, quantification of aceteyl bromide lignin in the stem cell walls of $\sim 6$-month-old plants revealed that the average lignin content of control lines was $\sim 23 \%$ of tissue dry weight, whereas of the MOMT4 transgenic lines ranged from 19 to $20 \%$, indicating a moderate level of lignin reduction (Fig. 2f). When the monomeric composition of lignin was determined using the diagnostic thioacidolysis method that primarily cleaves $\beta-O-4$-ether linkages interconnecting the lignin subunits ${ }^{30}$, we found that the amount of released S monomers from MOMT4 overexpression lines exhibited $63-74 \%$ reduction compared with the control lines; in contrast, the amount of released G-units was very similar, with an approximate level of $400 \mu \mathrm{mol} \mathrm{g}^{-1}$ dried cell wall residues (Fig. $2 \mathrm{~g}$ ). Correspondingly, the $\mathrm{S} / \mathrm{G}$ ratio of lignin had fallen from a value of 2:1 in the controls to $1: 2$ in the MOMT4 overexpression lines (Fig. $2 \mathrm{~g}$ ). These data suggest that expression of MOMT4 in hybrid aspen substantially alters lignin composition, and that the incorporation of the S-lignin monomer (sinapyl alcohol) was principally impaired in the cell walls of MOMT4 transgenics.

Two-dimensional heteronuclear single-quantum coherence (2D HSQC) NMR experiments further verified the reduction of S-units in lignins from MOMT4 transgenic lines. The detected signals from the S-units of two independent MOMT4 transgenic lines exhibited $>50 \%$ depletion over than those of the control lines; the calculated S/G ratio changed from 1.7 in the control lines to 0.4 in the MOMT4 overexpression aspens (Fig. 3a,b; Supplementary Fig. 2), consistent with the thioacidolysis results.
In both the thioacidolytic and NMR analyses, the detected amount of the $p$-hydroxyphenyl $(\mathrm{H})$ units was extremely low, and was not significantly different between the MOMT4 overexpression and control lines (Figs 2 and 3 ).

The aliphatic region of 2D HSQC NMR spectra reflects the changes in the types and distribution of inter-unit linkages present in the lignin fraction. The lignin from the control lines was rich in $\beta$-aryl ether units with modest amounts of resinols and low amounts of phenylcoumarans, as well as modest levels of the cinnamyl alcohol end groups (Fig. 3c; Supplementary Fig. 3). Resinols ( $\beta$ - $\beta$-coupled units) mostly arise from the dimerization of sinapyl alcohol. The spectra of lignin derived from MOMT4 transgenic aspens revealed that the resinol and $\beta$-aryl ether units were decreased by $25 \%$ compared with the controls, consistent with the lower amount of syringyl monomers released by thioacidolysis and documented in 2D HSQC NMR spectra. However, the phenylcoumaran ( $\beta-5$-coupled) structures that require at least one guaiacyl unit for their formation increased on average by more than fourfold over the controls (Fig. 3d; Supplementary Fig. 3). The level of cinnamyl alcohol end groups that also primarily arise from coniferyl alcohol (G-unit) monomer-monomer coupling ${ }^{3}$, rose about 1.5 -fold (Fig. 3d; Supplementary Fig. 3). These data affirm that lignin polymer from MOMT4 transgenic aspens is richer in the condensed linkages (for example, $\beta-5$ structures), and may be more branched or simply have shorter chains, as hinted by its increased end group units. Indeed, gel permeation chromatography revealed that the distribution of molecule weight $\left(M_{\mathrm{r}}\right)$ in the milled wood lignin fraction is lower in the
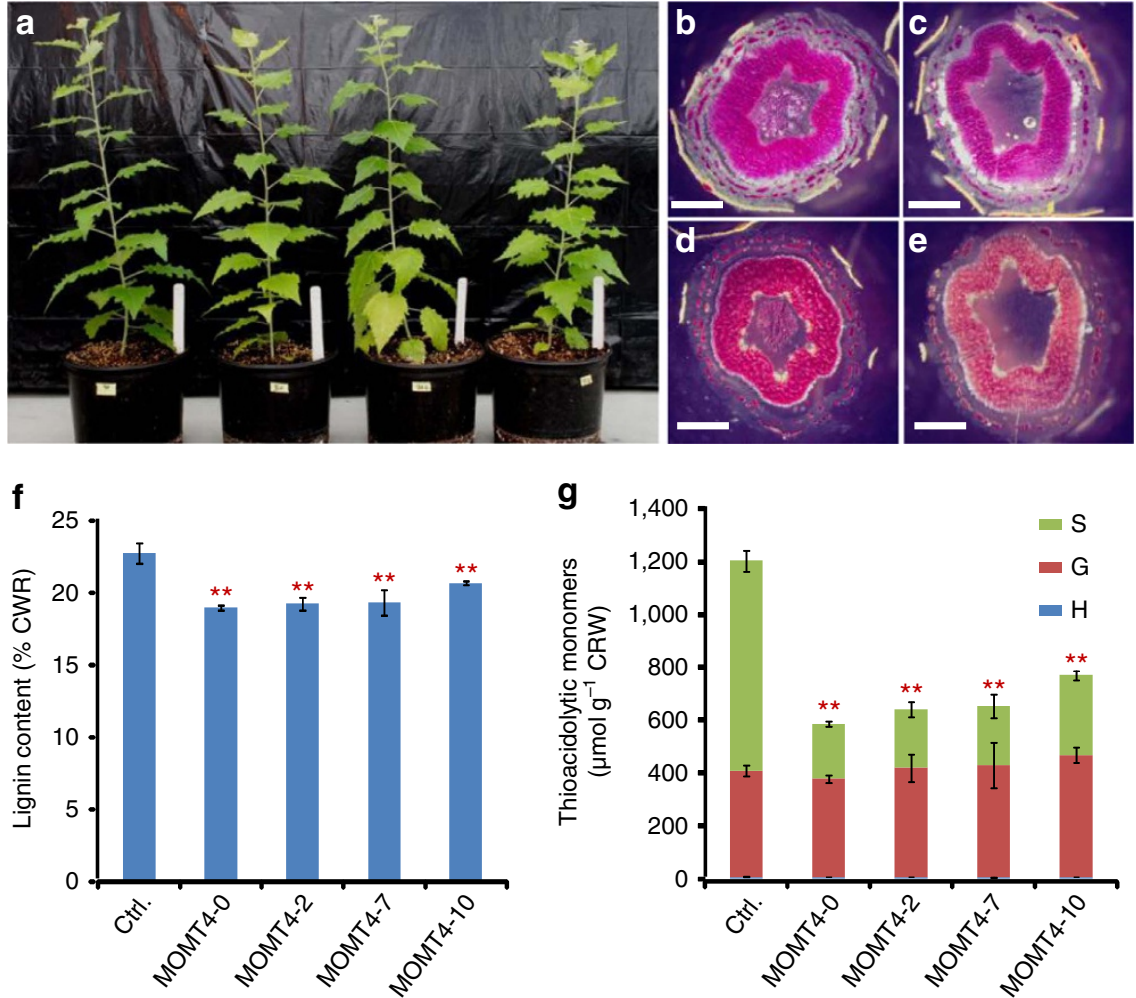

Figure 2 | The effect of expression of MOMT4 on content and composition of lignin in transgenic aspens. (a) Three-month-old hybrid aspens of control (left) and three MOMT4 independent transgenic lines (right). (b,c) Phloroglucinol-HCl staining of the stem cross-sections of control (b) and MOMT4-0 transgenic line (c). (d,e) Mäule staining of the stem cross-sections of control (d) and MOMT4-0 transgenics (e). Scale bars, $1 \mathrm{~mm}$. (f) Acetyl bromide total lignin content in the cell walls of control and MOMT4 transgenic aspen stems. (g) The monomers released by thioacidolysis from the stem cell walls of MOMT4 transgenic aspens; $\mathrm{S}$, syringyl; $\mathrm{G}$, guaiacyl; $\mathrm{H}$, p-hydroxyphenyl; CWR, cell wall residues; Ctrl., control. Data in f,g represent mean \pm s.e. with three biological replicates (each with three technical repeats) for the control and three technical repeats for the individual transgenic lines. ${ }^{\star \star}$ Indicates significant difference of lignin content (f) or S-monomer (g) compared to the control with $P<0.01$ (Student's $t$-test). 


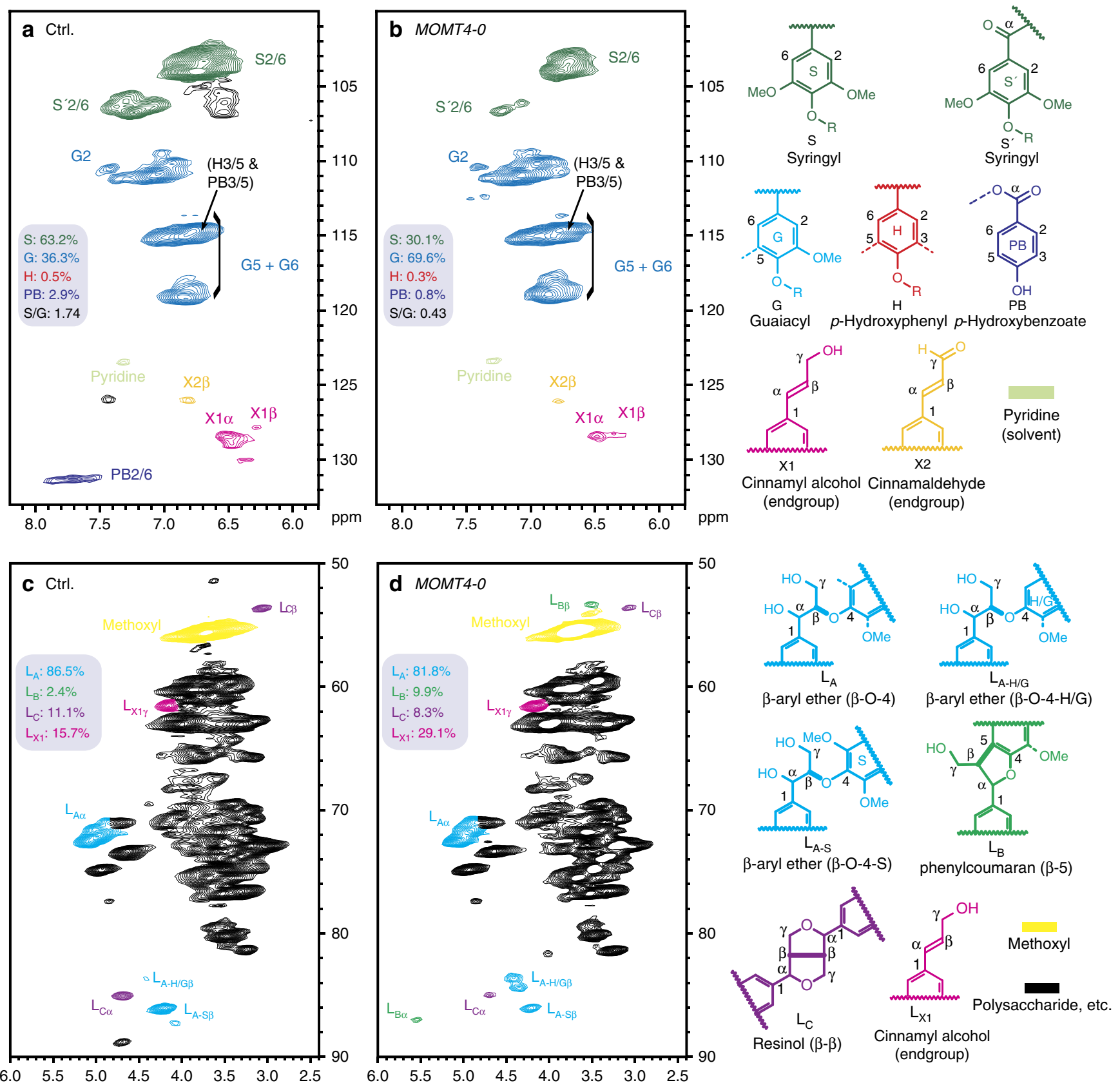

Figure 3 | 2D HSQC NMR spectral analysis of lignin structure in MOMT4 transgenic aspens. (a,b) Partial short-range 2D HSQC NMR spectra (aromatic region) of equal amounts of solubilized total cell walls of control and MOMT4 transgenic plants. The main structural units are coloured to coincide with their structures on the right. (c,d) Partial short-range 2D HSQC NMR spectra of lignin aliphatic and polysaccharide region of the same samples. The main units, characterized by their inter-unit linkages, are coloured to coincide with their structures to the right. See Supplementary Figs 2 and 3 online for the complete set of spectra of the transgenic and control samples.

MOMT4 transgenics compared with the control samples (Fig. 4), suggesting a lower degree of polymerization.

Alteration of wall-bound phenolics. Hydroxycinnamates (for example, $p$-coumarate and ferulate) and hydroxybenzoates that bond with the cell walls' non-cellulosic polysaccharides and lignin via ester linkages can act as crosslinkers or play a role in altering the oxidative potential of monolignols ${ }^{31}$. In poplar cell walls, the prominent 'wall-bound' phenolic is $p$-hydroxybenzoate that predominantly acylates syringyl units ${ }^{32,33}$. Examining the wallbound phenolics from the stems of MOMT4 transgenics revealed that the levels of both $p$-hydroxybenzoate and $p$-coumarate showed about a 50\% reduction, whereas the average amount of ferulate essentially was unchanged, compared with those in the control lines (Fig. 5). Both $p$-hydroxybenzoate and $p$-coumarate were proposed to conjugate with sinapyl alcohol within the cell and then incorporate into lignin polymer ${ }^{31}$. The reduction of both $p$-hydroxybenzoate and $p$-coumarate esters was consistent with the decreased incorporation of S-lignin monomers.

Alteration of cell wall polysaccharides. Along with changes of lignin content and structure of MOMT4 transgenic aspens, the total cellulose content was found to have increased from $51 \%$ of the dried cell wall residues in the controls, to a maximum of $57 \%$ in the MOMT4 overexpression lines, that is, by up to a $12 \%$ 


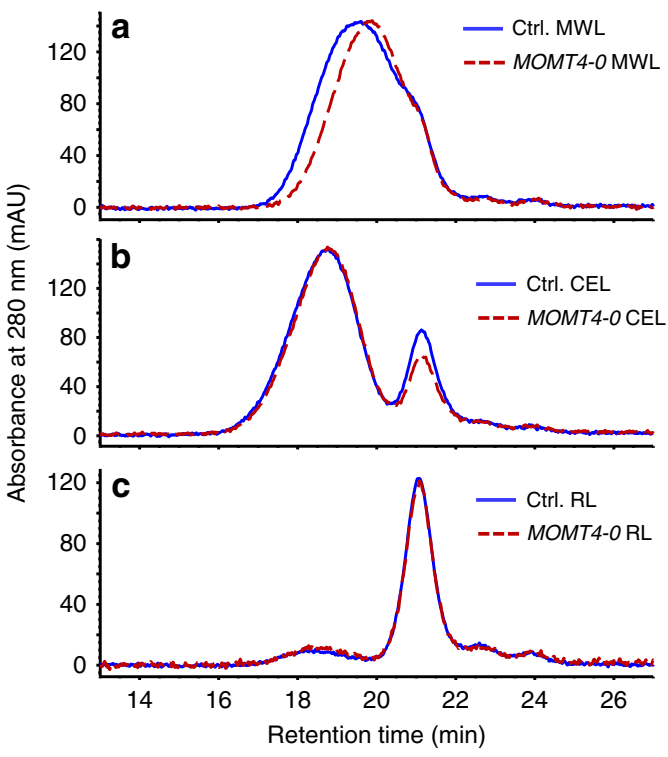

Figure 4 | Molecular weight profiles of different lignin fractions from the cell walls of MOMT4 transgenic and control plants. (a) The lignins extracted from the ball-milled woods of control and MOMT4-0 transgenic plants (referred to as MWL). (b) The lignins extracted from remaining materials after extraction of MWL, followed by a cellulolytic enzyme digestion (termed as CEL). (c) The lignins extracted from remaining wood residuals after extraction of MWL and CEL (referred to as RL). The prepared lignins were further acetylated and then analysed by HPLC.

increase (Fig. 6a). Synchrotron FT-IR imaging further verified that the polysaccharide level in the developing xylem of the stem cross-section of MOMT4 transgenics was substantially higher than that of the controls, whereas the level of lignification in the same developing wood tissues was lower (Supplementary Fig. 4). Along with the increase in total cellulose content, the levels of crystalline cellulose in the walls of MOMT4 transgenics was also increased by up to $15 \%$ over the levels of the controls (Fig. 6b), suggesting an ultrastructural change of cellulose fibres. When hemicelluloses were quantified, we found that their abundance in the cell walls was essentially unchanged, accounting for about $22.6 \%$ of the cell wall dry mass in the control, and an average 23.2\% (range 20.7-25.5\%) in the transgenic lines (Fig. 6c). The detected amount of hemicellulosic monomeric sugars also remained essentially the same in most lines, except the glucose content, which may have arisen from the amorphous regions of cellulose fibres, which was slightly higher in one of the transgenics (Supplementary Table 1). These data demonstrate that the alteration of lignin content and structure in MOMT4-overexpressing aspens affects the accumulation and ultrastructure of cellulose fibres, whereas it has less effect on the deposition of hemicelluloses.

Enhanced cellulolytic efficiency and ethanol yield. When the prepared wood cell walls were treated with a cellulase mixture, all of the examined MOMT4 transgenic samples displayed 50\%-62\% more weight loss than the controls, indicative of the release of more simple sugars and a higher degree of digestibility (Fig. 7a). Subsequently, two sets of the transgenic and control woods, one from 6-month-old newly propagated plantlets and another from $\sim 1$-year-old basal stem grown from the trees after three coppice events, underwent 'simultaneous saccharification and fermentation'6 to measure ethanol production. Both the MOMT4 transgenic woods and control ones either were treated with alkali (Supplementary Fig. 5a) or left untreated; then after washing the pretreated samples with water, the woody powders were
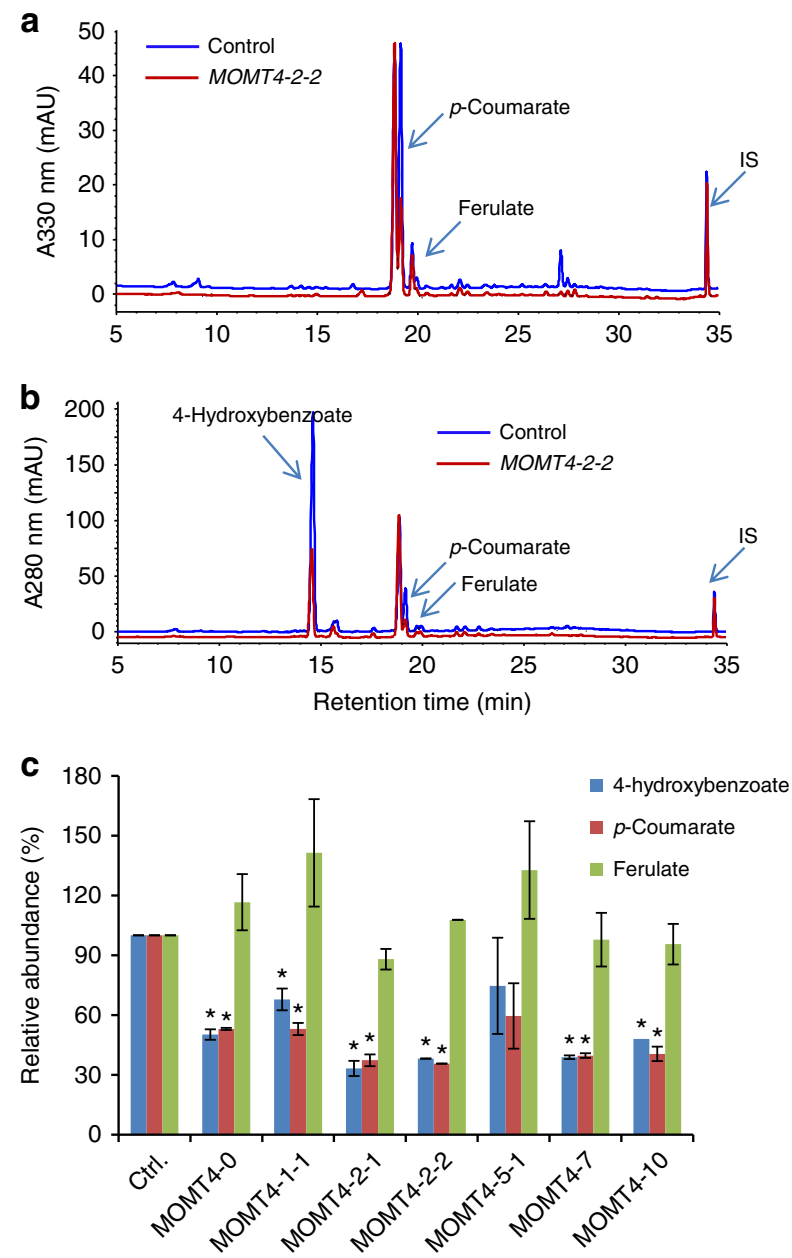

Figure 5 | Alteration of the accumulated wall-bound phenolics in stem cell walls of MOMT4 transgenic aspens. (a,b) UV-HPLC profiles of wall-bound phenolic extract from MOMT4-2-2 stem cell walls with ultraviolet absorbance at $330 \mathrm{~nm}$ (a) and $280 \mathrm{~nm}$ (b), respectively, to optimally display different phenolics; IS, internal standard. (c) Calculated relative abundance of the detected wall-bound phenolics in the individual MOMT4 transgenic lines. The averaged amount detected in the control lines was set as $100 \%$. Data were from five biological replicates (each with two technical repeats) for the control set and two to three technical repeats for the individual transgenic lines. Error bar stands for s.d. *Indicates significant difference compared to the corresponding controls with $P \leq 0.05$ (Student's $t$-test).

incubated with polysaccharidase enzymes and yeast cells in the fermentation broth. During incubation, we measured the weight loss caused by the release of fermentation gases and the ethanol content in the broth. The data showed that both the pretreated and non-pretreated transgenic woods displayed both a faster and higher fermentative weight loss (that is, the gas release), indicating a higher rate of saccharification and bioconversion compared to the control woods (Fig. 7b; Supplementary Fig. 5b). Correspondingly, higher yields of ethanol were realized compared to their respective controls (Fig. 7c; Supplementary Fig. 5c). When simultaneous saccharification and fermentation proceeded for $168 \mathrm{~h}$, the alkaline-pretreated and non-pretreated wood samples from 6-month-old MOMT4 transgenic plantlets showed up to $24 \%$ and $49 \%$ increase in ethanol yield, respectively (Fig. 7c). For alkaline-pretreated and non-pretreated wood samples from $\sim 1$-year-old basal stem of the primary transgenic plants, ethanol yield increased up to $40 \%$ and $48 \%$, respectively, 

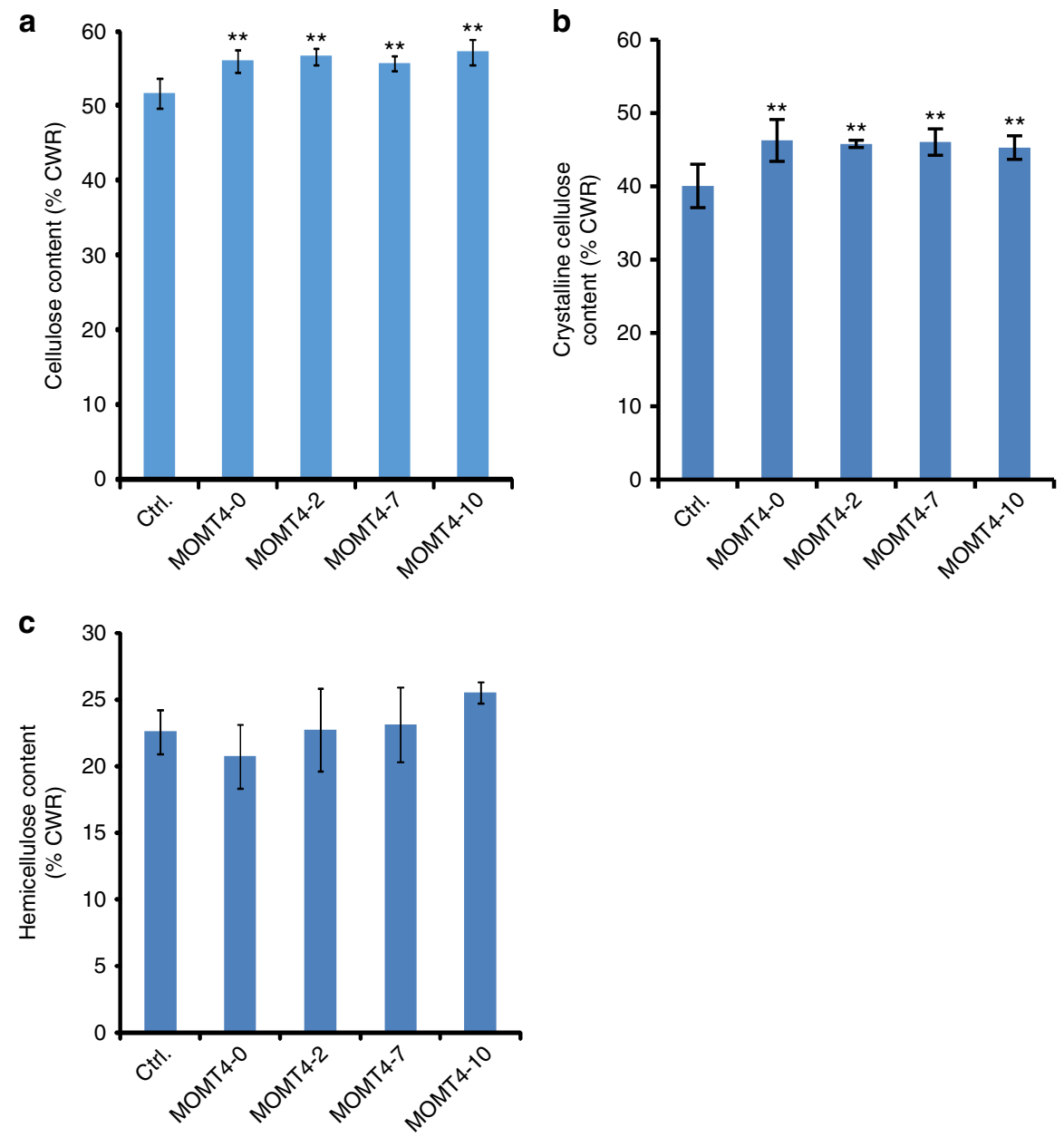

Figure 6 | The effect of expression of MOMT4 on accumulation of carbohydrates in transgenic aspens. (a) Cellulose content in the cell walls of control and MOMT4 transgenic aspens. (b) The crystalline cellulose content in MOMT4 transgenic cell walls. (c) Total hemicelluloses content in the cell walls of control and MOMT4 transgenic aspens. CWR, cell wall residues; Ctrl., Control. Data in a,b represent mean \pm s.d. from three biological replicates (each with eight technical repeats) for the control set and eight technical repeats for MOMT4 OE lines. ${ }^{\star \star} P<0.01$ (Student's $t$-test). Data in $\mathbf{c}$ represent mean \pm s.e. with three biological replicates (each with three technical repeats) for the control and three technical repeats for transgenic lines. No statistic difference between the transgenic and the control line was detected.

compared with the controls (Supplementary Fig. 5c). These data indicate that even though the MOMT4 transgenic woods contain a relatively higher level of condensed lignin, their digestibilities and bioconversion rates were substantially improved.

Growth and wood anatomy of transgenic aspens. Although the MOMT4 transgenic aspens exhibited substantial changes in both lignin and cellulose contents and structures, they exhibited normal growth and development in the greenhouse (Fig. 8). The average stem heights, basal stem thicknesses and total dried biomass yields of 3-and/or 6-month-old transgenic trees were statistically similar to those of the controls, notwithstanding the substantial variation among individual transgenic and control plants (Fig. 8a; Supplementary Table 2). The measured wood density of a set of primary transgenic lines, on average, was the same as in the control lines (Fig. 8b). At the cellular level, MOMT4 transgenic aspens developed a normal vasculature, and no collapsed vessel or fibre cells was observed, except that the lumina of their fibres appeared slightly narrower than those of the control line (Fig. 8c,d). These data suggest that expression of MOMT4 and the alteration of the composition and structure of lignin do not significantly compromise the aspen trees' growth or their production of woody biomass.
Syringyl lignin related gene expression and enzyme activity. Sinapyl alcohol biosynthesis branches from coniferyl alcohol/ aldehyde biosynthesis in the pathway by the sequential catalyses of coniferaldehyde/ferulate 5-hydroxylase (Cald5H/F5H) and COMT. We hypothesized that the reduced S-lignin content in the transgenics might have resulted from the potential inhibitory effect of 4-O-methylated monolignols, the products of MOMT4, on the activities of the biosynthetic enzymes specific for syringyl monomers. We therefore conducted substrate-inhibition assays using the prepared 4-O-methylated coniferyl and sinapyl alcohols on the recombinant aspen enzymes, Cald5H/F5H, COMT, CAD ((hydroxy)cinnamyl alcohol dehydrogenase), and a homologue of the previously identified poplar SAD (sinapyl alcohol dehydrogenase $)^{34}$, as well as on the crude enzyme extracts (for COMT, CAD/SAD, and peroxidase activities). Except for the recombinant $\mathrm{CAD}$ and the $\mathrm{SAD}$ homologue ${ }^{34}$, where their activities showed a 3-14\% inhibition when incubated with 4-O-methylated monolignols (Supplementary Table 3), there was no obvious inhibition on the activities of other recombinant enzymes (Supplementary Table 3). Consistent with a previous study $^{24}$, the 4-O-methylated monolignols did not impair the peroxidase-mediated oxidative polymerization process of the conventional monolignols (Supplementary Fig. 6). 

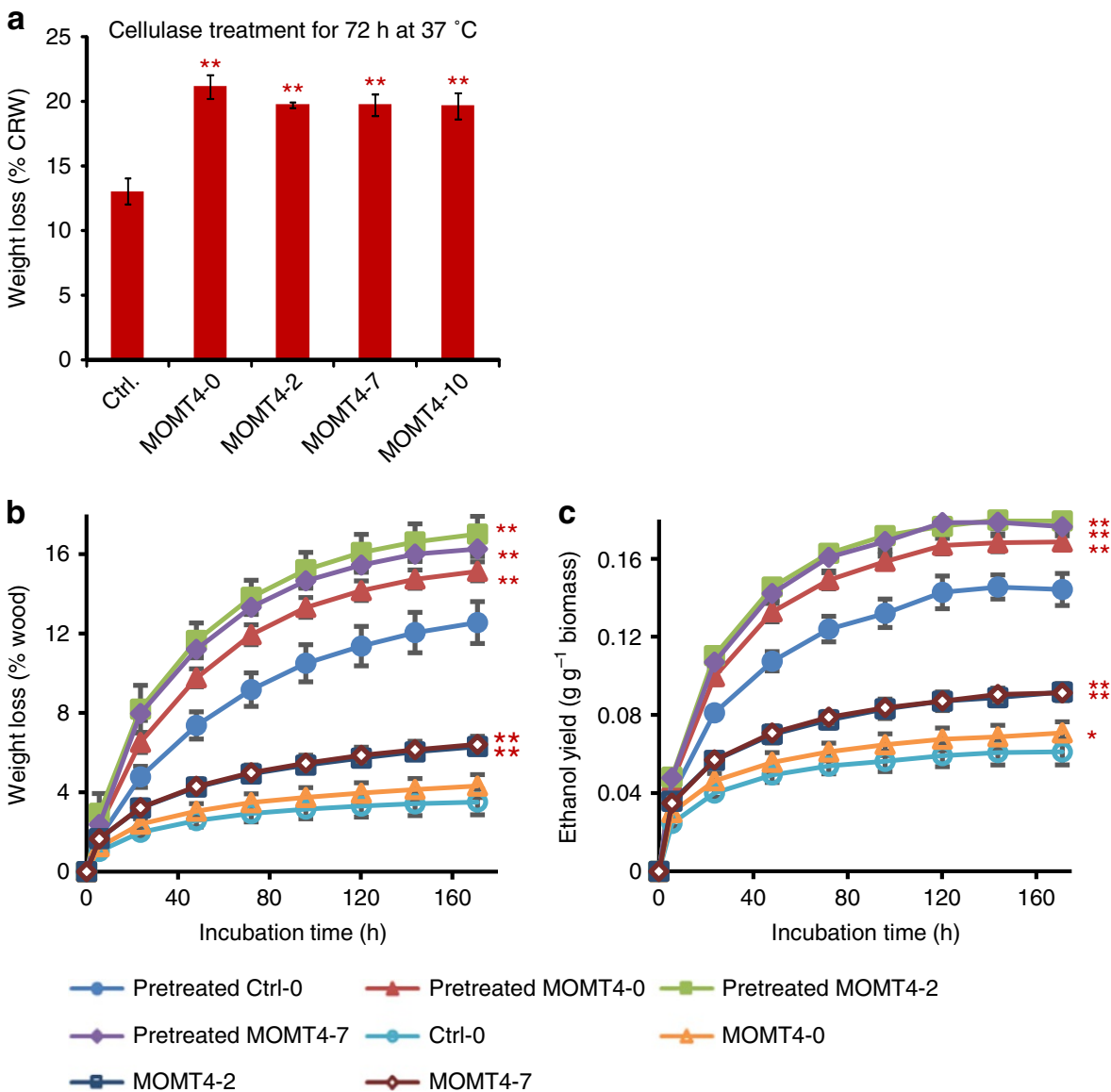

Figure 7 | Enzymatic hydrolysis and bioconversion of MOMT4 transgenic woods to ethanol. (a) Digestive weight loss when the prepared wood cell walls were treated with $2 \mathrm{mg} \mathrm{ml}^{-1}$ of cellulase for $72 \mathrm{~h}$ at $37^{\circ} \mathrm{C}$. Data represent mean \pm s.e. with three biological replicates (each with two to three technical repeats) for the control and three technical repeats for transgenic lines. CWR, Cell wall residues. ${ }^{\star \star} P<0.01$ (Student's $t$-test). (b,c) Broth weight loss (Fermentation gas release) (b) and ethanol yield (c) during simultaneous saccharification and fermentation of the pretreated and untreated control and MOMT4 transgenic woods. Data represent mean \pm s.d. of three biological replicates (each replicate with two experimental repeats for each control and transgenic lines. ${ }^{\star} P<0.05,{ }^{\star} * P<0.01$ (Student's $t$-test).

Considering the potential global transcriptional effect of the expression of MOMT4 on the cell wall and the lignin biosynthetic genes, we conducted a transcriptomic analysis on an MOMT4 overexpression line using RNA-seq. The data indicated that although the transcripts of MOMT4 transgene were highly abundant, which verifies the overexpression of the MOMT4 gene and demonstrates the reliability of RNA-seq dataset, none of the lignin biosynthetic genes exhibited substantial changes in their transcript abundances compared with those of the control set. Quantitative RT-PCR analysis on a set of xylem-specific lignin biosynthetic genes ${ }^{35}$ further validated that the transcripts of monolignol-branch genes, particularly the S-lignin synthetic genes, Cald5H/F5H, COMT, CAD and SAD homologue, did not exhibit significant differences between MOMT4 transgenic and control lines, although transcripts of a few genes in individual control or MOMT4 transgenic lines appeared to be outliers (Supplementary Fig. 7). Interestingly, RNA-seq data indicated that, among a small set of genes showing an altered transcript abundance, a few are annotated to encode cell wall proteins, including an $\alpha$-expansin family of proteins that are potentially involved in cell wall loosening ${ }^{36}$, a glycosyl hydrolase (9B13) whose homologous members in the family of endo-1,4- $\beta$ glucanases were reported to participate in cellulose synthesis or assembly ${ }^{37}$, and the cell wall-localized proline-rich protein (Supplementary Table 4). These data suggest the potential involvement of those proteins/enzymes in the observed alteration of the cell wall structure and composition of the MOMT4 transgenic aspens.

\section{Discussion}

The production of biofuels and bio-based chemicals from woody biomass is limited by its recalcitrance to hydrolysis for releasing simple sugars. Most lignin elimination processes are inefficient and expensive for many applications. Reducing and/or structurally changing lignin by manipulating certain genes in the monolignol biosynthetic pathway can enhance the cell wall degradability ${ }^{1}$; however, this approach is often accompanied by impairment of plant growth and development that results in a severe penalty to biomass yield $6,12,13,17,18$. Plants seem, however, to be tolerant of a wide range of lignin compositional/structural changes. One measure of lignin structure is its G- and S-lignin unit composition. In general, a high $S / G$ ratio is associated with increased pulping yields ${ }^{38,39}$, or improved enzymatic release of sugars ${ }^{40}$. The present study demonstrated that expression of the MOMT4 enzyme that etherifies the phenolic moieties of monolignols preferentially disrupts S-lignin deposition in hybrid aspen, which leads to the production of a G-lignin-rich biopolymer. An increase in G-units would be expected to exacerbate lignin's condensation, complexity and thus 


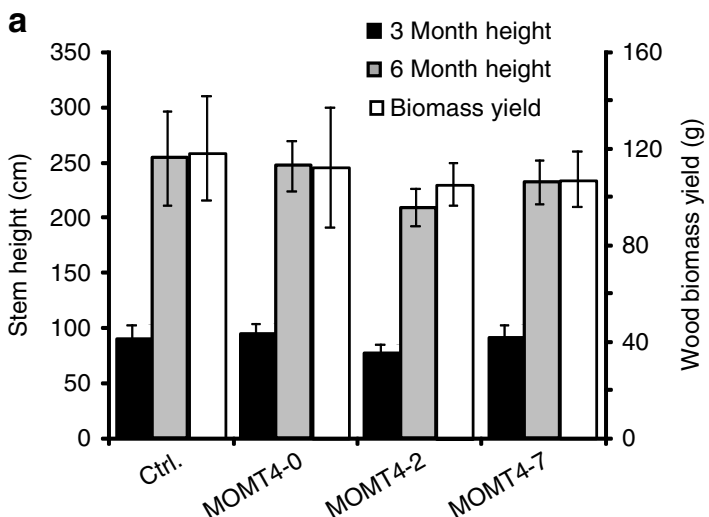

b

C
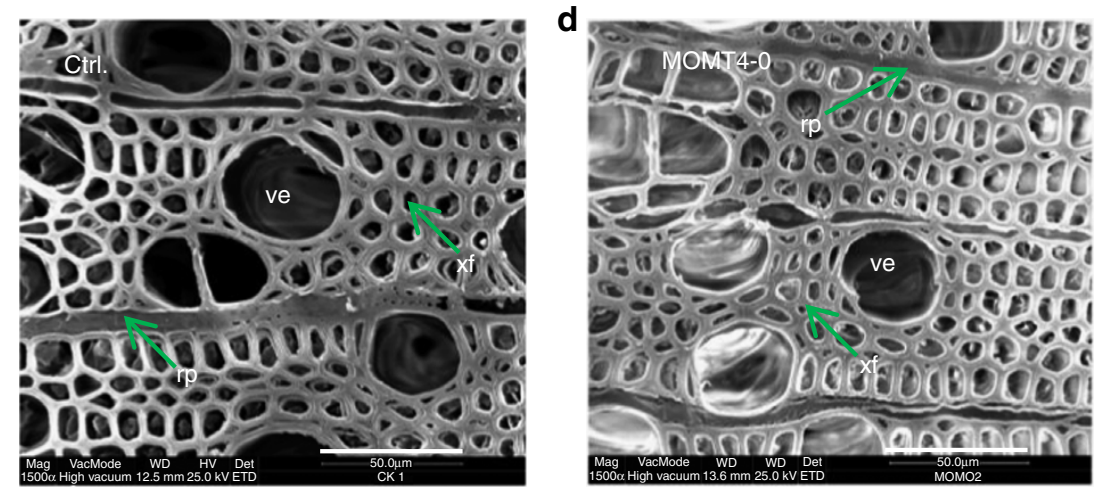

Figure 8 | Wood biomass yield, density and anatomy of MOMT4 transgenic aspen. (a) The measured stem height and dried wood biomass yield of 3- and/or 6-month-old plants of control and MOMT4 transgenics grown in a greenhouse. Data are mean \pm s.d. with three biological repeats for control and each transgenic line. (b) The calculated average wood density of the basal stems of $\sim 8$-month-old aspens. Data are mean \pm s.d. with six and eleven biological replicates (each replicate with three technical repeats) for control and transgenic plants, respectively. (c,d) Scanning electron micrographs

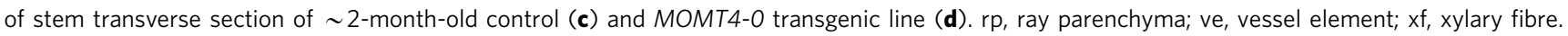
Scale bar, $50 \mu \mathrm{m}$.

recalcitrance of the cell walls. Surprisingly, the MOMT4 transgenics' woods displayed substantially improved efficiency in sugar release and had an enhanced bioconversion rate to ethanol. Up to $60 \%$ more woody biomass could be digested from transgenic cell walls than from the control wood under the same treatment, and up to $49 \%$ more ethanol resulted from the conversion of the non-pretreated transgenic woods, in comparison with the controls (Fig. 7; Supplementary Fig. 5). These results suggest that expression of MOMT4 in hybrid aspen leads to a significant alleviation of the recalcitrance to wood processing in an unexpected way, facilitating the conversion of woody biomass to liquid fuels. The improved wood digestibility of MOMT4 transgenic aspen may be attributed to several concurrent factors. For example, (1) the modest reduction of total lignin content in the cell wall that mitigates its physical barrier properties; (2) drastic structural alteration in lignin that may affect the association of lignin with polysaccharides and the interaction between cell wall biopolymers, thus changing the accessibility of the wall to digestive enzymes; (3) the relative increase of the content of cellulose fibres due to the cell wall's mass balance, which, in turn, enhances the source of fermentable six carbon sugars. Interestingly, altering lignin content and structure not only promoted cellulose deposition but also altered its ultrastructure; more crystalline cellulose microfibrils were formed in the MOMT4 transgenics' cell walls (Fig. 6). The underlying mechanisms for such concomitant alteration in polysaccharide deposition and structure remain unclear. One hypothesis is that S-lignin subunits and/or their linked hydroxybenzoate esters may play structural roles in the lignin-polysaccharide association. Disturbing S-lignin synthesis may trigger a potential feedback remodelling of cell wall carbohydrates. Alternatively, S-lignin deposition is regarded as one of the integral steps of plant secondary cell wall formation ${ }^{41}$; disrupting S-lignin synthesis may disturb or delay the cell wall's development processes, sustaining wood at a younger stage, and thus rendering it less recalcitrant to breakdown. Collectively, our study suggests that lignin condensation does not necessarily correlate to the digestibility of Populus, and it is not the sole or critical factor dominating cell wall recalcitrance.

Expression of MOMT4 in the herbaceous dicot Arabidopsis, and the woody species, aspen, yields quite different metabolic and biological consequences. When MOMT4 expressed in Arabidopsis, the plants produced both the 4-O-methylated feruloyl and sinapoyl malates in their soluble phenolic fraction ${ }^{25}$, suggesting that the 4-O-methylated products of MOMT4 entered the endogenous pathway of phenolic-ester biosynthesis that is specific for Brassicaceae species ${ }^{42,43}$. The total lignin content in the stem of transgenic Arabidopsis exhibited a significant reduction, while its composition and structure essentially remained unchanged $^{25}$. In contrast, when MOMT4 was expressed in aspen, the transgenic plant accumulated glucoconjugates of the 4-O-methyalted monolignols (Supplementary Fig. 1); furthermore, the lignin from transgenic tree was composed of a significantly lower level of S-subunits, and more condensed (C-C bonded) structures containing G-subunits (Figs 2 and 3) than occurred in the control aspen. This biological discrepancy may reflect the diversity and speciation of the phenylpropanoid metabolism, and the detoxification mechanism that the particular plants adopt, 
and also the species variability of plant lignifications. In particular, in terms of the distinct effects of MOMT4 on lignin synthesis in these two species, Populus hardwood is rich in syringyl lignin with an $\mathrm{S} / \mathrm{G}$ ratio ranging from 1.8 to $2.3^{44}$; whereas the lignin of Arabidopsis is guaiacyl rich (with $S / G$ ratio $\sim 0.25)^{45}$. Since MOMT4 displays a discernible, yet less dominant, substrate preference to sinapyl alcohol, when it is expressed in the guaiacyl-rich Arabidopsis, its kinetic effect may be masked or compromised. Whereas when MOMT4 acts in an environment in which the S-monomeric substrate is more prominently available, its kinetic propensities may result in its dominantly modifying sinapyl alcohol, and thus triggering a metabolic consequence entailing a more severe disruption of S-lignin formation. Such metabolic preference in fact was also evidenced with the higher level of accumulation of the 4-O-methylated sinapyl alcohol than the 4-O-methyalted coniferyl alcohol in the soluble phenolic fraction of transgenic aspen leaves and stems (Supplementary Fig. 1). Another possibility for preferentially reducing S-lignin in the transgenic aspens is that the MOMT4-produced 4-O-methylated compounds may exert inhibitory effects on the activities of Populus intrinsic S-lignin-specific enzymes. However, our in vitro study revealed that the 4-O-methylated monolignols have no detectable inhibitory effects on the activities of Cald5H/F5H or COMT from aspen; they only displayed a $3-14 \%$ inhibition on the activities of cinnamyl alcohol dehydrogenases (Supplementary Table 3). With such an inhibition, both the activities of CAD/ SAD to the G- and S- lignin precursors should be affected, which do not explain the observed preferential impairment of S-lignin synthesis (Supplementary Table 3). The exact reasons for expressing MOMT4 in aspen preferentially to disrupt S-lignin formation may be complicated. It remains to be determined whether this phenomenon is Populus specific or occurs in the other woody species.

Despite the drastic change in lignin and cell wall structure, those greenhouse-grown, $\sim 6$-month-old MOMT4 transgenic aspens showed no penalty in biomass yield, nor loss in wood density. The structural integrity at the whole plant- and cellularlevel was maintained essentially similar to that of the control (Fig. 8). The sustained growth and fitness features of MOMT4 transgenic aspens are most likely attributed to their attaining condensed G-lignin, the increased cellulose content, and the elevated crystallinity of cellulose fibres in their cell walls along with a concomitant decrease in S-lignin formation. We note that the current study, examining the plant growth property, was conducted in a relatively short period. An extended physiological investigation, or a field trial with the generated transgenic trees, will substantiate their viability as biofuel feedstocks.

In summary, expressing an engineered monolignol 4-O-methyltransferase in hybrid aspen substantially alters lignin structure while also producing more cellulose. Such alteration facilitates wood digestibility and its bioconversion to ethanol, proving a useful strategy to tailor woody biomass for bio-based applications. The created transgenic aspen represents a valuable feedstock for further industrial exploitation in biofuel production.

\section{Methods}

Overexpression of MOMT4 in hybrid aspen. Approximately $1.1 \mathrm{~kb}$ of the promoter of PAL2 from bean (Phaseolus vulgaris L.) was amplified from the vector pCAMBIA2200-GW (ref. 14) with a pair of primers that incorporated HindIII and KpnI restrictive enzyme sites, respectively (Supplementary Table 5). The 35S promoter of the vector pMDC32, a gateway destination vector ${ }^{46}$, was removed by the enzymatic digestion with HindIII and KpnI and replaced with bean PAL2 promoter; this yielded a binary vector pMDC32-PAL-GW. The open reading frame of the engineered MOMT4 gene was then integrated into the created binary vector following the standard gateway cloning procedures (Invitrogene). The resulting
} MOMT4 expression construct was transferred into Agrobacterium tumefaciens strain GV3101 for plant transformation. Hybrid aspen clone INRA 717-IB4 (P. tremula $\mathrm{x} P$. alba) was propagated and transformed using the protocol of $\mathrm{Ma}$ et al. ${ }^{47}$ Briefly, leaf disc and stem segment explants, after wounding with multiple fine cuts, were co-cultivated for $1 \mathrm{~h}$ with A. tumefaciens strain GV3101 containing the MOMT4 expression construct. Then, the explants were cultivated on callus induction medium (CIM, 0.025\% (w/v) 2-(N-morpholino)ethanesulfonic acid (MES), $0.01 \%(\mathrm{w} / \mathrm{v}$ ) myo-inositol, $0.43 \%$ (w/v) $1 / 2$ MS basal salts, $3 \%$ sucrose, $10 \mu \mathrm{M}$ 1-naphthaleneacetic acid, $5 \mu \mathrm{M}$ 2-isopentyladenine, $\mathrm{pH} 5.8$ ) at $22^{\circ} \mathrm{C}$ in dark for 2 days. After washing with distilled water, the explants were subsequently cultured in dark on CIM containing $10 \mathrm{mgl}^{-1}$ hygromycin and $200 \mathrm{mgl}^{-1}$ timentin for selecting the transformed calli. After 2-3 weeks, the explants were sub-cultured on shoot selection medium $(0.025 \%(\mathrm{w} / \mathrm{v})$ MES, $0.01 \%(\mathrm{w} / \mathrm{v})$ myo-inositol, $0.43 \%$ (w/v) $1 / 2$ MS basal salts, $3 \%$ sucrose, $1 \%$ (v/v) FV vitamins) containing $0.2 \mu \mathrm{M}$ thidiazuron, $10 \mathrm{mgl}^{-1}$ hygromycin and $200 \mathrm{mgl}^{-1}$ timentin for 2-3 months and sub-cultured every 3-4 weeks. The explants with multiple shoots were then transferred onto the shoot selection medium supplemented with $0.1 \mu \mathrm{M}$ 6-benzylaminopurine, $10 \mathrm{mgl}^{-1}$ hygromycin and $200 \mathrm{mgl}^{-1}$ timentin for shoot elongation. The regenerated shoots were further screened for hygromycin resistance and induced for roots on $1 / 2$ MS medium supplemented with $0.5 \mu \mathrm{M}$ indole-3-butyric acid, $10 \mathrm{mgl}^{-1}$ hygromycin and $100 \mathrm{mgl}^{-1}$ timentin. After $\sim 30$ days, the elongated, rooted shoots were transferred into the soil.

The generated primary transgenic plants were examined by RT-PCR for the expression of the MOMT4 transgene, phenolic profiling and preliminary total lignin content determination. The selected primary transgenic clones were then propagated. Briefly, the nodal and tip explants were taken from actively growing shoots of coppiced plantlets. After sterilizing them, they were placed in Yellow medium ${ }^{47}$ and sub-cultured frequently until a uniformly continuous growth of new shoots was obtained. The shoots then were harvested and rooted in the rooting medium ${ }^{47}$. The generated plantlets were transferred into the pots, and maintained in the greenhouse at $25^{\circ} \mathrm{C}$ under high illumination at $500 \mu \mathrm{mol} \mathrm{m}^{-2} \mathrm{~s}-1$. When the plants were fully established, they were then illuminated by natural light. The transgenic and control plants intended for lignin and phenolic analysis were grown side by side.

Methanolic soluble phenolic profiling. Approximately 2-month-old plantlets of the control lines and the MOMT4 transgenic lines were harvested. All the leaves on a shoot of about $30 \mathrm{~cm}$ (above ground), and the shoot itself (without bark) were collected from individual lines and ground into fine powders under liquid nitrogen. Approximately $0.2 \mathrm{~g}$ of the leaf or stem powders were extracted overnight with $1 \mathrm{ml}$ $80 \%$ methanol (containing $20 \mu \mathrm{M}$ chrysin as the internal standard). Then, $25 \mu \mathrm{l}$ extracts of leaf, or $200 \mu \mathrm{l}$ extracts of stems after solvent evaporation were digested

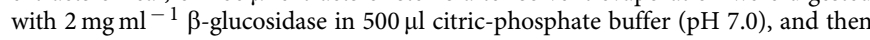
re-extracted with ethyl acetate. After drying them under a steam of $\mathrm{N}_{2}$, the ethyl acetate extracts were re-dissolved in $100 \mu \mathrm{l}$ methanol, and $30 \mu \mathrm{l}$ was taken for HPLC analysis. For ultraviolet-HPLC profiling, the samples were resolved in a mobile phase of $0.2 \%$ acetic acid (A) with an increasing concentration gradient of acetonitrile containing $0.2 \%$ acetic acid (B) at $0-2 \mathrm{~min}, 5 \%(\mathrm{~B}) ; 2-30 \mathrm{~min}, 5$ to $50 \%$ (B); $30-32 \mathrm{~min}, 50$ to $100 \%$, and then $100 \%$ for $2 \mathrm{~min}$ at a flow rate of $1 \mathrm{ml} \mathrm{min}^{-1}$. The ultraviolet absorption was monitored at 254-, 280-, 310- and 330-nm using a multiple-wavelength photodiode array detector. The detected compounds were quantified based on their peak areas and calculated against the standard curves of conifery alcohol and sinapyl alcohol as they exhibit nearly the same ultraviolet absorption property as do their 4-O-methylated compounds.

The 4-O-methylated coniferyl alcohol and sinapyl alcohol used for identifying the leaf metabolites were synthesized by the MOMT4-catalysed reactions as described below in the section of Enzyme activity inhibition assay.

For characterizing the novel metabolites by GC-MS, the leaf extracts after $\beta$-glucosidase digestion were re-extracted with ethyl acetate. After drying under $\mathrm{N}_{2}$ gas, the residuals from the extracts were derivatized with $30 \mu \mathrm{l}$ pyridine and $30 \mu \mathrm{l}$ MSTFA at room temperature for $4 \mathrm{~h}$, and then dried under a stream of N2 gas. Dichloromethane $(60 \mu \mathrm{l})$ were used to dissolve the samples. Around $1 \mu \mathrm{l}$ was injected for GC-MS analysis. The mass spectra of two distinct metabolites in the chromatographs of transgenic samples were recorded.

Histochemical analyses. Histochemical analyses was performed on $30-\mu \mathrm{m}$-thick sections taken from the same position of basal node of 2-month-old shoots of the control and MOMT4 transgenic aspens. For phloroglucinol (Wiesner) staining, the fresh sections were left for $5 \mathrm{~min}$ in $1 \%$ phloroglucinol in $95 \%$ ethanol and mounted in $6 \mathrm{~N} \mathrm{HCl}$. For Mäule staining, the stem sections were immersed in $1 \%$ (w/v) potassium permanganate solution for $5 \mathrm{~min}$ at room temperature and then washed with water and acidified with $3 \%$ hydrochloric acid until partially decoloured. Sections were finally mounted in ammonia or $5 \% \mathrm{NaHCO}_{3}$ and examined quickly. Photographs were taken by using a Leica stereomicroscope system with a Leica DFC 300 colour camera.

Analysis of wall-bound phenolics and lignin. Aspen stems were harvested from 6-month-old plants. Segments of basal stems $\sim 30 \mathrm{~cm}$ long, taken from each of the transgenic and control lines, were peeled to remove bark, dried and then ground in a Wiley mill. The milled wood chips were passed through a $60-\mu \mathrm{m}$ mesh sieve. The 
wood powders were then extracted with $70 \%$ ethanol at $65^{\circ} \mathrm{C}$ for $3 \mathrm{~h}$. This process was repeated for three times. The residuals were further extracted three times with chloroform/methanol $(1: 1, \mathrm{v} / \mathrm{v})$, and then treated overnight with acetone at room temperature. The extracted free residuals were dried at $45^{\circ} \mathrm{C}$ and then ball-milled into a fine powder. The wall-bound phenolics were extracted with $2 \mathrm{~N} \mathrm{NaOH}$ in the dark at $37^{\circ} \mathrm{C}$ for $16 \mathrm{~h}$. After neutralization of the reaction with concentrated $\mathrm{HCl}$, the hydrolysate was extracted with water-saturated ethyl acetate twice. The extract was dried under stream of $\mathrm{N}_{2}$ gas then dissolved in $100 \mu \mathrm{l} 80 \%$ methanol and analysed using HPLC with the aforementioned method (in soluble phenolics profiling section).

Total lignin was quantified by the acetyl bromide method ${ }^{48}$. Extractive-free wood powders $(5 \mathrm{mg}$ ) were incubated with $1 \mathrm{ml} 25 \%$ acetyl bromide in acetic acid at $70^{\circ} \mathrm{C}$ for $30 \mathrm{~min}$. After cooled down and diluted with $5 \mathrm{ml}$ acetic acid, $300 \mu \mathrm{l}$ solution was aliquoted and neutralized with $400 \mu \mathrm{l} 1.5 \mathrm{M} \mathrm{NaOH}$ and $300 \mu \mathrm{l} 0.5 \mathrm{M}$ hydroxylamine hydrochloride. The neutralized sample was further diluted with $1.5 \mathrm{ml}$ acetic acid and the absorbance at $280 \mathrm{~nm}$ was measured. The extinction coefficient of $18.21 \mathrm{~g}^{-1} \mathrm{lcm}^{-1}$ was used for the calculation of lignin content.

The thioacidolysis method ${ }^{49}$ was followed to estimate the monomeric composition of lignin. Briefly, for each sample, $10 \mathrm{mg}$ of extractive-free wood powders were mixed with $1 \mathrm{ml}$ of freshly prepared reaction mixture $(2.5 \%$ boron trifluoride etherate and $10 \%$ ethanethiol in distilled dioxane $(\mathrm{v} / \mathrm{v}))$ in a $2 \mathrm{ml}$ glass vial and flushed with $\mathrm{N}_{2}$ gas. Then the vial was tightly sealed and heated at $95^{\circ} \mathrm{C}$ for $4 \mathrm{~h}$ with periodic agitation. The reaction was stopped by placing on ice for $15 \mathrm{~min}$ and then its $\mathrm{pH}$ value was brought to $3-4$ by using $0.4 \mathrm{M}$ sodium bicarbonate. The reaction solution was transferred to a new $10 \mathrm{ml}$ vial; $2 \mathrm{ml}$ water was added. Meanwhile, $1 \mathrm{mg}$ tetracosane (dissolved in $1 \mathrm{ml}$ methylene chloride as internal standard) was added to each vials. The vial was recapped, vortexed, then allowed to settle for more than half hour until phase separation of the solution occurred. An aliquot $(1.5 \mathrm{ml})$ of the organic phase was taken and passed through a Pasteur pipette packed with an inch of anhydrous sodium sulfate. The filtrate was then evaporated to the dryness and resuspended in $0.5 \mathrm{ml}$ of methylene chloride. Samples $(50 \mu \mathrm{l})$ were then dried and derivatized with pyridine and $\mathrm{N}$-methyl- $\mathrm{N}$ (trimethylsilyl) trifluoroacetamide (Sigma) at room temperature for $5 \mathrm{~h}$ Quantifying the corresponding monomers was accomplished via a gas chromatography-flame ionization detector on a GC instrument (Agilent 7890A) after an appropriate calibration relative to the tetracosane internal standard.

Whole-cell wall NMR analyses. The pre-ground cell walls were extracted with distilled water (ultrasonication, $1 \mathrm{~h}$, three times) and $80 \%$ ethanol (ultrasonication, $1 \mathrm{~h}$, three times). Isolated cell walls were dried and ball-milled in a Planetary micro mill Pulverisette 7 premium line (Fritsch, Idar-Oberstein, Germany) at 600 r.p.m., using $\mathrm{ZrO}_{2}$ vessels $(20 \mathrm{ml})$ containing $\mathrm{ZrO}_{2}$ ball bearings $(10 \times 10 \mathrm{~mm})$. Each sample $(180 \mathrm{mg}$ ) was ground for $1 \mathrm{~h} 10 \mathrm{~min}$ (interval: $10 \mathrm{~min}$, break: $5 \mathrm{~min}$, repeated nine times). The cell walls $(60 \mathrm{mg})$ were collected directly into the NMR

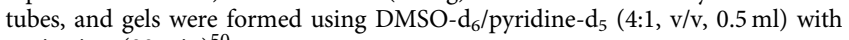
sonication $(30 \mathrm{~min})^{50}$.

NMR spectra were acquired on a Bruker Biospin (Billerica, MA, USA) Avance $700 \mathrm{MHz}$ spectrometer equipped with a cryogenically cooled 5-mm quadrupleresonance ${ }^{1} \mathrm{H} /{ }^{3} \mathrm{P} /{ }^{13} \mathrm{C} /{ }^{15} \mathrm{~N}$ QCI gradient probe with inverse geometry (proton coils closest to the sample). The central DMSO solvent peak was used as an internal reference $\left(\delta_{\mathrm{C}} 39.5, \delta_{\mathrm{H}} 2.49\right.$ p.p.m.). The ${ }^{1} \mathrm{H}^{13}{ }^{13} \mathrm{C}$ correlation experiment was an adiabatic HSQC experiment (Bruker standard pulse sequence 'hsqcetgpsisp2.2'; phase-sensitive gradient-edited-2D HSQC using adiabatic pulses for inversion and refocusing). HSQC experiments were carried out using the following parameters: acquired from 11.5 to -0.5 p.p.m. in F2 $\left({ }^{1} \mathrm{H}\right)$ with 1,682 data points (acquisition time $100 \mathrm{~ms}), 215$ to -5 p.p.m. in $\mathrm{F} 1\left({ }^{13} \mathrm{C}\right)$ with 620 increments ( $\mathrm{F} 1$ acquisition time $8.0 \mathrm{~ms}$ ) of 32 scans with a $0.5 \mathrm{~s}$ interscan delay (D1); the $\mathrm{d}_{24}$ delay was set to $0.86 \mathrm{~ms}(1 / 8 \mathrm{~J}, J=145 \mathrm{~Hz})$. The total acquisition time for a sample was $5 \mathrm{~h}$. Processing used typical matched Gaussian apodization $(\mathrm{GB}=0.001, \mathrm{LB}=-0.5)$ in F2, and squared cosine-bell and one level of linear prediction (32 coefficients) in F1. Volume integration of contours in HSQC plots used Bruker's TopSpin 3.1 (Mac) software. Assignments of peaks from NMR spectra were based on previous publications $\mathrm{s}^{50}$

Cellulose quantification and cellulolytic analysis. For cellulose content determination, the control and transgenic wood powders (passed through a 60 -mesh sieve) were sequentially treated with $75 \%$ ethanol, chloroform/methanol mixture (1:1), and acetone as described above, then resuspended in $0.1 \mathrm{~N}$ sodium acetate ( $\mathrm{pH}$ 5.0) and mixed with $5 \mu \mathrm{g}$ amylase (Sigma) to each sample to incubate at $37^{\circ} \mathrm{C}$, overnight. After digestion, the recovered powders were washed with water and acetone, respectively, three times, the powders were then dried at $35^{\circ} \mathrm{C}$ and further ground using a ball mill. Cellulose content was measured according to the Updegraff's method ${ }^{51}$. For determining crystalline cellulose content, we adopted the trifluoroacetic acid (TFA)-phenol-sulfuric assay ${ }^{52}$. Briefly, $\sim 1 \mathrm{mg}$ extract-free cell wall residuals were mixed with $1 \mathrm{ml}$ of $2 \mathrm{M}$ trifluoroacetic acid and heated at $121^{\circ} \mathrm{C}$ for $90 \mathrm{~min}$, with applying a vortex every $30 \mathrm{~min}$ to break up the chunks. After centrifugation, we removed the supernatant representing non-cellulose monosaccharides and amorphous cellulosic sugars, and then the pellets were collected and washed. The pellets next were suspended in $100 \mu \mathrm{l}$ of $50 \mathrm{mM}$ sodium acetate buffer (pH 4.8) and $100 \mu l$ freshly made 5\% phenol, and then briskly mixed with $1 \mathrm{ml}$ concentrated sulfuric acid. The orange colour was developed at $30^{\circ} \mathrm{C}$ in $2 \mathrm{~h}$, and its intensity was quantified at $500 \mathrm{~nm}$. Glucose was used as the authentic standard.

The susceptibility to cellulolytic breakdown was evaluated using a method described by Sibout ${ }^{53}$. Extract-free samples $(200 \mathrm{mg})$ were placed in $30 \mathrm{ml}$ of $50 \mathrm{mM}$ sodium acetate buffer ( $\mathrm{pH} \mathrm{4.8)}$, containing $2 \mathrm{mg} \mathrm{ml}^{-1}$ of Cellulase (Onozuka R-10, PhytoTechnology Laboratories), and incubated at $37^{\circ} \mathrm{C}$ for $72 \mathrm{~h}$ under magnetic stirring. After incubation, the reaction medium was filtered over a filtering crucible. The residue then was washed with water, oven-dried and gravimetrically determined.

Hemicelluloses quantification. The determination of the content of hemicelluloses and the composition of their monomeric sugar followed the alditol acetate method described ${ }^{54}$. The alcohol extractive-free samples firstly were treated with amylase and pullulanase (Sigma) in a $50 \mathrm{mM}$ sodium acetate buffer ( $\mathrm{pH} 4.8$ ) overnight to remove starch. The de-starched material then was hydrolyzed with $2 \mathrm{M}$ TFA at $121^{\circ} \mathrm{C}$ for $60 \mathrm{~min}$. The released sugars were reduced to their corresponding alditols by adding $0.5 \mathrm{M}$ freshly prepared sodium borohydride solution (in dimethyl sulfoxide) at $40^{\circ} \mathrm{C}$ for $90 \mathrm{~min}$. After neutralizing with acetic acid, the alditols were incubated with acetic anhydride and 1-methylimidazole for acetylation. The resultant alditol acetates were finally dissolved in dichloromethane and separated on a gas chromatograph that was equipped with a $30 \mathrm{~m} \times 0.25-\mathrm{mm}$ (internal diameter) Agilent J \&W HP-5MS capillary column, and the eluant introduced into a mass spectrometer (Agilent Technologies); the initial oven temperature was maintained at $38^{\circ} \mathrm{C}$ for $30 \mathrm{~s}$, increased to $170^{\circ} \mathrm{C}$ at $50^{\circ} \mathrm{C} \mathrm{min}^{-1}$ and then increased to $230^{\circ} \mathrm{C}$ at $2^{\circ} \mathrm{C} \mathrm{min}-1$ and held there for $5 \mathrm{~min}$. The individual sugars were identified by comparison with authentic standard compounds; their quantitation was based on the standard curves of each derivatized individual sugar made from the same GC-MS run.

FT-IR spectroscopic imaging. Infrared imaging of the sections of poplar stems followed the method described by Gou et al. ${ }^{55}$ Briefly, a piece of aspen stem from $\sim 1$ month-old plantlet within the first five internodes was cut and fresh-frozen over liquid nitrogen. Then, the specimen was embedded in Tissue-Tek freezing medium and sectioned with a cryomicrotome (Leica Microsystems) at $-20^{\circ} \mathrm{C}$. Sections $(10 \mu \mathrm{m}$ thick) were placed on a BaF2 microscope slide and dried at room temperature. IR images were collected using a Perkin Elmer Spectrum Spotlight FT-IR Imaging System (Waltham, MA, USA) with a $6.25-\mu \mathrm{m}$ pixel resolution. For each tissue section, a light micrograph was obtained, and the regions to be imaged with the IR microscope were defined. Infrared images were collected in the transmission mode by raster-scanning the sample through the IR beam, and collecting infrared absorbance spectra at each pixel. For each pixel, an entire infrared spectrum is obtained from 4,000- to $720-\mathrm{cm}^{-1}$. Background spectra were gathered from a clean region of the $\mathrm{BaF}_{2}$ slide. The spectral resolution was $8 \mathrm{~cm}^{-1}$, and 16 scans were averaged for each spectrum.

The corresponding FT-IR image was created by visualizing the intensity of the spectra at $1,510 \mathrm{~cm}^{-1}$, which was assigned to the vibration of the phenolic ring from lignin ${ }^{56}$ and the spectra bands from 900 - to $1,180-\mathrm{cm}^{-1}$, representing the overlapped polysaccharides. Both sets of images were normalized to the $\mathrm{C}-\mathrm{H}$ intensity to correct for any variation in sample thickness; empty pixels covering cells' lumens were eliminated by setting a threshold limit for the absorbance at lignin and polysaccharides.

Determination of lignin molecular weight. The lignin fractions were prepared essentially as described ${ }^{57}$ with minor modifications. Briefly, the prepared poplar cell walls were further intensively milled using a Retsch ball mill PM100 for $5 \times 10 \mathrm{~min}$ with $5 \mathrm{~min}$ pause in between. The ball-milled materials were extracted twice with 96:4 dioxane:water. The extracts were pooled and freeze-dried, resulting in the milled wood lignin (MWL). The insoluble materials were then treated at $30^{\circ} \mathrm{C}$ with a crude cellulase mixture (Onozuka R-10, PhytoTechnology Laboratories). The materials were extracted twice more with 96:4 dioxane:water. The extracts were pooled and freeze-dried, giving rise to so-called cellulolytic enzyme lignins (CEL). The remaining insoluble materials were referred to as residue lignin (RL). The different lignin materials were then dissolved in $N$ methylimidazole (NMI) and dimethyl sulfoxide in a ratio of 1:2 and acetylated by adding acetic anhydride $(0.6 \times \mathrm{NMI})^{58}$. Analyses of the molecular weight for different lignin fractions were performed by HPLC with a PHENOGEL Linear (2) column $(00 \mathrm{H}-3259-\mathrm{K} 0)$ using tetrahydrofuran as the mobile phase. The flow rate was set at $0.5 \mathrm{ml} \mathrm{min}^{-1}$

Fermentation of aspen wood. Basal stems $(\sim 30 \mathrm{~cm})$ from 6-month-old newly propagated MOMT4 transgenic and control plantlets, or from 1-year-old primary transgenic trees after three coppice events were harvested, air dried and milled to fine powder (passing through a $60-\mu \mathrm{m}$ mesh sieve). The materials were used directly for fermentation or were pretreated as follows: the wood powders were mixed with $1 \% \mathrm{Ca}(\mathrm{OH})_{2}$ at the ratio of $10 \%(\mathrm{w} / \mathrm{v})$ biomass, and treated at $121^{\circ} \mathrm{C}$ for $6 \mathrm{~h}$. The treated powders were collected by centrifuging, and then

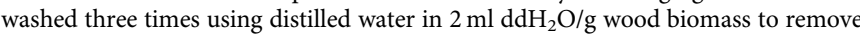
the soluble materials. The pretreated wood powders then were completely dried at 
$45^{\circ} \mathrm{C}$. Simultaneous saccharification and fermentation was undertaken following an established protocol ${ }^{6}$ with slight modification. Briefly, the fermentation was carried out in capped aseptic bottles containing $8 \%(\mathrm{w} / \mathrm{v})$ woody biomass (either pretreated or untreated), $1 \%(\mathrm{w} / \mathrm{v})$ yeast extract, and $2 \%(\mathrm{w} / \mathrm{v})$ bactopeptone in $50 \mathrm{mM}$ sodium citrate buffer ( $\mathrm{pH}$ 4.8). After autoclaving them, we added accellerase 1500 (DuPont, WI, USA) that contains multiple enzyme activities, including endoglucanase $\left(2,200-2,800 \mathrm{CMC} \mathrm{U} \mathrm{g}^{-1}\right)$, and $\beta$-glucosidase (450-775 pNPG U g${ }^{-1}$ ), at $0.3 \mathrm{ml} \mathrm{g}^{-1}$ biomass, and yeast (Saccharomyces cerevisiae D5A, ATCC 200062) at a final $\mathrm{OD}_{600}$ of 0.5 in the total fermentation reaction volume of $12.5 \mathrm{ml}$. The broth was incubated at $37^{\circ} \mathrm{C}$ in a shaker at 175 r.p.m. to prevent sedimentation of the substrate, and the yeast. At the indicated incubation time, we recorded the weight of the aseptic bottle containing the fermentation broth and then the bottle was vented using a hyperdermic needle. After allowing for adequate equilibration of the pressure and temperature of the bottle (about $30 \mathrm{~min}$ ), the needle was removed from the bottle and the bottle was weighed again. The difference of the weight before and after ventilation represents the weight loss (that is, gas release) of fermentation. Then, an aliquot of broth ( $\sim 20 \mu \mathrm{l})$ was taken from the bottles; after centrifuging, the supernatant was collected and stored for later determining its ethanol content. Ethanol was detected and quantified with Agilent GC7690A equipped with a capillary column (Alltech EC-WAX, $30 \mathrm{~m} \times 0.32 \mathrm{~mm} \times 0.25 \mu \mathrm{m}$, Econo-Cap, GRACE), and a flameionization detector. The analysis was carried out under the following conditions: Oven temperature, $45^{\circ} \mathrm{C}$ for $6 \mathrm{~min}$, then programmed to $180^{\circ} \mathrm{C}$ at a rate of $35^{\circ} \mathrm{C} \mathrm{min}^{-1}$, and held there for $2 \mathrm{~min}$; the temperature of both the injector and detector was $225^{\circ} \mathrm{C}$; the nitrogen (carrier gas) total flow rate was $14 \mathrm{ml} \mathrm{min}^{-1}$; the hydrogen flow rate was $30 \mathrm{ml} \mathrm{min}^{-1}$; and the air flow rate was $400 \mathrm{ml} \mathrm{min}^{-1}$, , and the flow rate of the column gas was $1 \mathrm{ml} \mathrm{min}^{-1}$; Samples were diluted 10 -fold; the injection volume was $1 \mu \mathrm{l}$, with a split ratio of 25:1. n-Propanol was used as an internal standard for calibration. We used the standard curve of ethanol made in the same GC-FID run for quantifying the yield of fermentation ethanol.

Wood density. Approximately 8-month-old control plants and MOMT4 primary transgenic plants were harvested. After removing their bark, the primary stems then were dried at $45^{\circ} \mathrm{C}$. The basal part of the stem of each line was then cut into three sections (each $\sim 5 \mathrm{~cm}$ ), the dry weight (Ws) of each section was measured first; the volume of each section was then measured in a graduated cylinder filled with fine glass beads (soda lime with diameter at $0.5 \mathrm{~mm}$, Biospect Prodcuts). The volume of glass beads before and after inserting stem section was recorded and termed $V 0$ and $V 1$, respectively. The volume of each stem was calculated with $V s=V 1-V 0$. The density of the wood was calculated as $D s=W s /(V 1-V 0)$. The data from six control lines and eleven transgenic lines were averaged, respectively.

Scanning electron microscopy. The 16th nodes from the top of 2-month-old aspen shoots of MOMT4 transgenic- and control lines were fixed in $2.5 \%$ glutaraldehyde and $1 \%$ formaldehyde in $0.2 \mathrm{M}$ sodium phosphate buffer ( $\mathrm{pH} 7.0$ ). Thereafter, the samples were washed with the buffer three times and the lower $1 \mathrm{~cm}$-stem segments of both the transgenic- and the control lines were prepared and cut at $50 \mu \mathrm{m}$ with a Leica VT $1000 \mathrm{~S}$ vibratome (Leica Microsystems, Heidelberg, Germany). Five sections each from the transgenic- and control-lines were prepared and imaged with optical microscopes. The remaining stem segments were then dehydrated in a series of graded ethanol solution and dried with a Polaron critical-point drying apparatus (Polaron Instruments Inc., Doylestown, PA, USA). The samples were mounted on aluminium stubs, sputter-coated with gold, and the vibratome cutting faces were imaged at $25 \mathrm{kV}$ and in high vacuum mode with a Quanta 200 environmental scanning electron microscope (FEI Company, Hillsboro, OR, USA).

Enzyme activity inhibition assay. To prepare 4-O-methylated monolignols, the purified MOMT4 enzyme was incubated in a reaction mixture containing $50 \mathrm{mM}$ Tris-HCl (pH 7.5), $2 \mathrm{mM}$ coniferyl alcohol or sinapyl alcohol, $10 \mathrm{mM}$ SAM and $1 \mathrm{mM}$ DTT. The reaction proceeded at $30^{\circ} \mathrm{C}$ for $2 \mathrm{~h}$ to produce 4 -O-methylated coniferyl alcohol (4OMeCA) or 4-O-methylated sinapyl alcohol (4OMeSA). After extraction with water-saturated ethyl acetate, the organic phase was dried under stream of nitrogen gas. The purity of products was examined by HPLC, and the authenticity was confirmed by LC-MS.

For poplar gene cloning and enzyme preparation, the total RNAs were extracted using a CTAB-based method ${ }^{59}$ from wild-type hybrid aspen. The first strand cDNA was synthesized using M-MuLV Reverse Transcriptase (New England Biolabs) under the manufacture recommended conditions. Cinnamyl alcohol dehydrogenase genes PtrCAD and PtrSAD, and P450 membrane-bound enzyme gene $P \operatorname{trF} 5 \mathrm{H}$ were amplified by RT-PCR, respectively, using primers listed in Supplementary Table 5. The PCR products were then subcloned into pCR8-GW/TOPO vector with the standard procedure (Invitrogen) to obtain the corresponding gateway cloning entry vectors. The constructs were verified by sequencing. PtrCAD and PtrSAD were then introduced by the LR reaction into a gateway-compatible vector, pETG-41K (http://www.helmholtz-muenchen.de), and transformed into BL21-CodonPlus (DE3)-RIPL (Agilent). The recombinant proteins were purified by Ni-NTA affinity chromatography. The aspen stem's crude proteins (PtrSTEX) were extracted using the procedure described ${ }^{60}$ with minor modifications. Briefly, the developing stems of 3-month-old wild-type aspens were harvested and ground into a fine powder under liquid nitrogen. The powder was extracted with a $20 \mathrm{mM}$ Tris- $\mathrm{HCl}$ (pH 7.5) buffer containing $10 \mathrm{mM}$ ascorbate, 1.5\% PVPP and $1 \mathrm{mM}$ PMSF. After centrifuging at $10,000 \mathrm{~g}$ for $20 \mathrm{~min}$ at $4{ }^{\circ} \mathrm{C}$, the supernatant was filtered through a $0.45 \mu \mathrm{m}$ membrane and stored at $-70^{\circ} \mathrm{C}$ for further use. PtrF5H was cloned into pYES-DEST52 and transformed into the yeast strain WAT11 for expression. Incubation of yeasts and induction of protein expression were performed by using high-density procedure ${ }^{61}$. After induction with $20 \%$ galactose for $18 \mathrm{~h}$, yeast cells were harvested and disrupted with Zymolasa 100T (Seikagaku, Tokyo). After centrifuging at 12,000 $\mathrm{g}$ for $10 \mathrm{~min}$, the resulting supernatant were then ultra-centrifuged at $140,000 \mathrm{~g}$ for $90 \mathrm{~min}$. The microsomal pellet was resuspended in assay buffer ( $50 \mathrm{mM}$ sodium Pipes $(\mathrm{pH} 7.0)$ containing $20 \%$ glycerol and $4 \mathrm{mM}$ disodium EDTA) and stored at $-80^{\circ} \mathrm{C}$. PtrCOMT was cloned from Populus trichocarpa and its recombinant enzyme was expressed and produced in Escherichia coli BL21(DE3) strain ${ }^{62}$

The cinnamyl alcohol dehydrogenase activity was measured essentially as described $^{34}$. Briefly, a $50 \mu \mathrm{l}$ reaction contained $50 \mathrm{mM}$ Tris- $\mathrm{HCl}(\mathrm{pH} 7.5), 1 \mathrm{mM}$ $\beta$-mercaptoethanol, $0.5 \mathrm{mM}$ NADPH, and $0.5 \mathrm{mM}$ hydroxycinnamaldehyde. PtrCAD $(1.5 \mu \mathrm{g}), 5 \mu \mathrm{g}$ PtrSAD, or $2 \mu \mathrm{g}$ PtrSTEX was used in the reaction with sinapaldehyde as the substrate; $3 \mu \mathrm{g}$ PtrCAD, $15 \mu \mathrm{g}$ PtrSAD, or $10 \mu \mathrm{g}$ PtrSTEX was used in the reaction with coniferaldehyde as the substrate. PtrF5H activity was measured according to Humphreys et al. ${ }^{63}$ using $1 \mathrm{mM}$ coniferyl alcohol as a substrate in a $50 \mu \mathrm{l}$ reaction containing $39.25 \mu \mathrm{l}(29.7 \mathrm{mg}$ protein per $\mathrm{ml})$ microsome. For assaying COMT activity, the reaction mixture containing $100 \mathrm{mM}$ Tris- $\mathrm{Cl}$ (pH 7.5), $1 \mathrm{mM}$ DTT, $500 \mu \mathrm{M}$ SAM, and $500 \mu \mathrm{M}$ caffeic acid and $1.5 \mu \mathrm{g}$ purified PtrCOMT or $20 \mu \mathrm{g}$ PtrSTEX was incubated at $30^{\circ} \mathrm{C}$ for $5 \mathrm{~min}$. All the enzyme assays were conducted either in the presence or absence of $40 \mu \mathrm{M}$ 4-O-metylated -coniferyl alcohol or -sinapyl alcohol to examine their potential inhibition on the activity. The enzymatic products were profiled using HPLC following the method described above.

In vitro polymerization assay. $500 \mu \mathrm{M}$ coniferyl alcohol or sinapyl alcohol was incubated with $40 \mathrm{ng}$ horseradish peroxidase (Sigma), and $1.14 \mathrm{mM} \mathrm{H}_{2} \mathrm{O}_{2}$ in $25 \mathrm{mM}$ Tris-Cl buffer (pH 7.5) in the presence or absence of $40 \mu \mathrm{M} 4 \mathrm{OMeCA}$ or $4 \mathrm{OMeSA}$. The reaction was preceded for $10 \mathrm{~min}$ at $30^{\circ} \mathrm{C}$. The products were extracted by water-saturated ethyl acetate, dried under the stream of $\mathrm{N}_{2}$ gas, then re-dissolved in $50 \mu \mathrm{l}$ of methanol and profiled by HPLC. A crude extract of aspen stem, PtrSTEX, was used for assaying peroxidase activity instead of HRP.

qRT-PCR analyses of monolignol biosynthetic genes. The 4th-13rd internodes of 2-month-old developing stems were harvested from two independent control lines and two MOMT4 transgenic lines (MOMT4-0 and MOMT4-2). For each line, two individual plants were respectively sampled. The total RNAs were extracted using a CTAB-based method ${ }^{59}$. First strand $\mathrm{CDNA}$ was synthesized using M-MuLV Reverse Transcriptase (New England Biolabs) under the manufacture recommended conditions. The selection of monolignol biosynthetic genes and primer designs were performed as described ${ }^{35}$ except PtrPT1 (ref. 64) was used as the reference gene. For each sample, qRT-PCRs were carried out in triplicates for all the genes examined with primers listed in Supplementary Table 5. SsoAdvanced Universal SYBR Green Supermix (Biorad) was used for the reaction. The cycle threshold $(\mathrm{Ct})$ value was calculated by the CFXManager Software v3.0 (Biorad). Gene expression was analysed using the comparative $\mathrm{Ct}$ method against the reference gene PtrPT1.

RNA sequencing. The 1st to 15th internodes from the top of 2-month-old hybrid aspen stems of MOMT4-0 transgenic and control lines were harvested and, after removing their barks, were immediately frozen in liquid nitrogen. About $100 \mathrm{mg}$ stem samples pooled from 2 to 3 individual transgenic and control plants, respectively, were grounded to fine powder under liquid nitrogen. Total RNAs were extracted using Qiagen RNeasy Plant Mini Kit (\#Cat. 74903) following the manufacturer recommended procedures. The assessment of purity and concentration of each RNA sample, and the strand-specific RNA-Seq library construction were conducted by using the Polar Genomics (Ithaca, NY, USA) service. Sequencing was done using the Illumina HiSeq2500 platform via 100-bp single-end reads of multiplexed RNA samples. The resulting RNA-Seq reads were aligned to the P. trichocarpa genome downloaded from the PlantGDB (http://www.plantgdb.org/ $\mathrm{XGDB} / \mathrm{ph}$ plib/download.php?GDB=Pt) using TopHat ${ }^{65}$ allowing one mismatch. Following these alignments, raw counts for each poplar gene were derived and normalized to reads per kilobase of exon model per million mapped reads (RPKM). The differentially expressed genes were identified with the integrated Cuffdiff programme $e^{66,67}$ based on False Discovery Rate adjusted $p$ value (that is, $q$ value) at the cutoff of 0.05 .

Statistical analysis. Statistical analysis was performed by Student's $t$-tests (two-tail distribution and two-samples with unequal variances). Statistically significant differences were defined as $P<0.05$. Values in graphs were presented as means with s.d. or s.e. Microsoft Excel 2011 (Microsoft Corporation) were used for data management, statistical analysis, and graph generation. 
Data availability. RNA-seq data described in this study has been deposited in the GEO Database under accession code GSE81123. The authors declare that all other data supporting the findings of this study are available within the article and its Supplementary Information files or are available from the corresponding author upon request.

\section{References}

1. Novaes, E., Kirst, M., Chiang, V., Winter-Sederoff, H. \& Sederoff, R. Lignin and biomass: a negative correlation for wood formation and lignin content in trees. Plant Physiol. 154, 555-561 (2010).

2. Andersson-Gunneras, S. et al. Biosynthesis of cellulose-enriched tension wood in Populus: global analysis of transcripts and metabolites identifies biochemical and developmental regulators in secondary wall biosynthesis. Plant J. 45, 144-165 (2006).

3. Ralph, J. et al. Lignins: natural polymers from oxidative coupling of 4-hydroxyphenylpropanoids. Phytochem. Rev. 3, 29-60 (2004).

4. Chen, F. \& Dixon, R. A. Lignin modification improves fermentable sugar yields for biofuel production. Nat. Biotechnol. 25, 759-761 (2007).

5. Fu, C. et al. Genetic manipulation of lignin reduces recalcitrance and improves ethanol production from switchgrass. Proc. Natl Acad. Sci. USA 108, 3803-3808 (2011)

6. Van Acker, R. et al. Improved saccharification and ethanol yield from field-grown transgenic poplar deficient in cinnamoyl-CoA reductase. Proc. Natl Acad. Sci. USA 111, 845-850 (2014).

7. Wilkerson, C. G. et al. Monolignol ferulate transferase introduces chemically labile linkages into the lignin backbone. Science 344, 90-93 (2014).

8. Tu, Y. et al. Functional analyses of caffeic acid $O$-methyltransferase and cinnamoyl-CoA-reductase genes from perennial ryegrass (Lolium perenne) Plant Cell 22, 3357-3373 (2010).

9. Xu, B. et al. Silencing of 4-coumarate:coenzyme A ligase in switchgrass leads to reduced lignin content and improved fermentable sugar yields for biofuel production. New Phytol. 192, 611-625 (2011).

10. Baxter, H. L. et al. Two-year field analysis of reduced recalcitrance transgenic switchgrass. Plant Biotechnol. J. 12, 914-924 (2014).

11. Bonawitz, N. D. \& Chapple, C. Can genetic engineering of lignin deposition be accomplished without an unacceptable yield penalty? Curr. Opin. Biotechnol. 24, 336-343 (2013)

12. Shadle, G. et al. Down-regulation of hydroxycinnamoyl CoA: Shikimate hydroxycinnamoyl transferase in transgenic alfalfa affects lignification, development and forage quality. Phytochemistry 68, 1521-1529 (2007).

13. Franke, R. et al. The Arabidopsis REF8 gene encodes the 3-hydroxylase of phenylpropanoid metabolism. Plant J. 30, 33-45 (2002).

14. Reddy, M. S. et al. Targeted down-regulation of cytochrome P450 enzymes for forage quality improvement in alfalfa (Medicago sativa L.). Proc. Natl Acad. Sci. USA 102, 16573-16578 (2005).

15. Coleman, H. D., Samuels, A. L., Guy, R. D. \& Mansfield, S. D. Perturbed lignification impacts tree growth in hybrid poplar--a function of sink strength, vascular integrity, and photosynthetic assimilation. Plant Physiol. 148, 1229-1237 (2008)

16. Wagner, A. et al. Suppression of 4-coumarate-CoA ligase in the coniferous gymnosperm Pinus radiata. Plant Physiol. 149, 370-383 (2009).

17. Voelker, S. L. et al. Antisense down-regulation of 4CL expression alters lignification, tree growth, and saccharification potential of field-grown poplar. Plant Physiol. 154, 874-886 (2010).

18. Voelker, S. L., Lachenbruch, B., Meinzer, F. C., Kitin, P. \& Strauss, S. H. Transgenic poplars with reduced lignin show impaired xylem conductivity, growth efficiency and survival. Plant Cell Environ. 34, 655-668 (2011).

19. Lee, M. H. \& Brewbaker, J. L. Effect of brown midrid-3 on yield and yield components of maize. Crop Sci. 24, 105-108.

20. Oliver, A. L., Pedersen, J. F., Grant, R. J. \& Klopfenstein, T. J. Comparative effects of the sorghum-6 and-12 Genes. Crop Sci. 45, 2234-2239 (2005)

21. Jung, J. H., Fouad, W. M., Vermerris, W., Gallo, M. \& Altpeter, F. RNA suppression of lignin biosynthesis in sugarcane reduces recalcitrance for biofuel production from lignocellulosic biomass. Plant Biotechnol. J. 10, 1067-1076 (2012).

22. Freudenberg, K. in Constitution and Biosynthesis of Lignin (eds Freudenberg, K. \& Neish, A. C.) 45-122 (Springer-Verlag, 1968).

23. Harkin, J. M. in Oxidative Coupling of Phenols (eds Taylor, W. I. \& Battersby, A. R.) 243-321 (Marcel Dekker, 1967).

24. Bhuiya, M. W. \& Liu, C. J. Engineering monolignol 4-O-methyltransferases to modulate lignin biosynthesis. J. Biol. Chem. 285, 277-285 (2010).

25. Zhang, K. W. et al. An engineered monolignol 4-O-methyltransferase (MOMT4) represses lignin polymerization and confers novel metabolic capability in Arabidopsis. Plant Cell 24, 3122-3139 (2012).

26. Wang, J. \& Pichersky, E. Characterization of S-adenosyl-L-methionine: (Iso)eugenol $\mathrm{O}$-methyltransferase involved in floral scent production in Clarkia breweri. Arch. Biochem. Biophys. 349, 153-160 (1998).
27. Ohl, S., Hedrick, S. A., Chory, J. \& Lamb, C. J. Functional properties of a phenylalanine ammonia-lyase promoter from Arabidopsis. Plant Cell 2, 837-848 (1990).

28. Liang, X., Dron, M., Schmid, J., Dixon, R. A. \& Lamb, C. J. Developmental and environmental regulation of a phenylalanine ammonia-lyase $B$-glucuronidase gene fusion in transgenic tobacco plants. Proc. Natl Acad. Sci. USA 86, 9284-9288 (1989).

29. Levee, V. \& Seguin, A. Inducible expression of the heterologous PAL2 promoter from bean in white pine (Pinus strobus) transgenic cells. Tree Physiol. 21, 665-672 (2001).

30. Lapierre, C. in Forage Cell Wall Structure and Digestibility (eds Jung, H. G. et al.) 133-166 (American Society of Agronomy, Crop Science Society of America, Soil Science Society of America, 1993).

31. Ralph, J. Hydroxycinnamates in lignification. Phytochem. Revs 9, 65-83 (2010)

32. Lu, F., Ralph, J., Morreel, K., Messens, E. \& Boerjan, W. Preparation and relevance of a cross-coupling product between sinapyl alcohol and sinapyl p-hydroxybenzoate. Org. Biomol. Chem. 2, 2888-2890 (2004).

33. Morreel, K. et al. Profiling of oligolignols reveals monolignol coupling conditions in lignifying poplar xylem. Plant Physiol. 136, 3537-3549 (2004).

34. Li, L. et al. The last step of syringyl monolignol biosynthesis in angiosperms is regulated by a novel gene encoding sinapyl alcohol dehydrogenase. Plant Cell 13, 1567-1585 (2001).

35. Shi, R. et al. Towards a systems approach for lignin biosynthesis in Populus trichocarpa: transcript abundance and specificity of the monolignol biosynthetic genes. Plant Cell Physiol. 51, 144-163 (2010).

36. Cosgrove, D. J. Plant expansins: diversity and interactions with plant cell walls. Curr. Opin. Plant Biol. 25, 162-172 (2015).

37. Takahashi, J. et al. KORRIGAN1 and its aspen homolog PttCel9A1 decrease cellulose crystallinity in Arabidopsis stems. Plant Cell Physiol. 50, 1099-1115 (2009).

38. Huntley, S. K., Ellis, D., Gilbert, M., Chapple, C. \& Mansfield, S. D. Significant increases in pulping efficiency in $\mathrm{C} 4 \mathrm{H}-\mathrm{F} 5 \mathrm{H}$-transformed poplars: improved chemical savings and reduced environmental toxins. J. Agric. Food Chem. 51, 6178-6183 (2003).

39. Lapierre, C. et al. Structural alterations of lignins in transgenic poplars with depressed cinnamyl alcohol dehydrogenase or caffeic acid $O$-methyltransferase activity have an opposite impact on the efficiency of industrial kraft pulping. Plant Physiol. 119, 153-163 (1999).

40. Studer, M. H. et al. Lignin content in natural Populus variants affects sugar release. Proc. Natl Acad. Sci. USA 108, 6300-6305 (2011).

41. Chapple, C. C. S., Vogt, T., Ellis, B. E. \& Somerville, C. R. An arabidopsis mutant defective in the general phenylpropanoid pathway. Plant Cell 4, 1413-1424 (1992).

42. Milkowski, C., Baumert, A., Schmidt, D., Nehlin, L. \& Strack, D. Molecular regulation of sinapate ester metabolism in Brassica napus: expression of genes, properties of the encoded proteins and correlation of enzyme activities with metabolite accumulation. Plant J. 38, 80-92 (2004).

43. Nair, R. B., Bastress, K. L., Ruegger, M. O., Denault, J. W. \& Chapple, C. The Arabidopsis thaliana REDUCED EPIDERMAL FLUORESCENCE1 gene encodes an aldehyde dehydrogenase involved in ferulic acid and sinapic acid biosynthesis. Plant Cell 16, 544-554 (2004).

44. Davison, B. H., Drescher, S. R., Tuskan, G. A., Davis, M. F. \& Nghiem, N. P. Variation of $S / G$ ratio and lignin content in a Populus family influences the release of xylose by dilute acid hydrolysis. Appl. Biochem. Biotechnol. 129-132, 427-435 (2006).

45. Meyer, K., Shirley, A. M., Cusumano, J. C., Bell-Lelong, D. A. \& Chapple, C. Lignin monomer composition is determined by the expression of a cytochrome P450-dependent monooxygenase in Arabidopsis. Proc. Natl Acad. Sci. USA 95, 6619-6623 (1998).

46. Curtis, M. D. \& Grossniklaus, U. A Gateway cloning vector set for high-throughput functional analysis of genes in planta. Plant Physiol. 133, 462-469 (2003).

47. Ma, C., Strauss, S. F. \& Meilan, R. Agrobacterium-mediated transformation of the genome-sequenced poplar clone, Nisqually-1 (Populus trichocarpa). Plant Mol. Biol. Rep 22, 1-9 (2004).

48. Chang, X. F., Chandra, R., Berleth, T. \& Beatson, R. P. Rapid, microscale, acetyl bromide-based method for high-throughput determination of lignin content in Arabidopsis thaliana. J. Agric. Food Chem. 56, 6825-6834 (2008).

49. Rolando, C., Monties, B. \& Lapierre, C. in Methods in Lignin Chemistry (eds Lin, S. Y. \& Dence, C. W.) 334-340 (Springer-Verlag, 1992).

50. Kim, H. \& Ralph, J. Solution-state 2D NMR of ball-milled plant cell wall gels in DMSO-d $\mathrm{d}_{6} /$ pyridine- $_{5}$. Org. Biomol. Chem 8, 576-591 (2010).

51. Updegraff, D. M. Semimicro determination of cellulose in biological materials. Anal. Biochem. 32, 420-424 (1969).

52. Dubois, M., Gilles, K. A., Hamilton, J. K., Rebers, P. A. \& Smith, F. Colorimetric method for determination of sugars and related substances. Anal. Chem. 28, 350-356 (1956). 
53. Sibout, R. et al. CINNAMYL ALCOHOL DEHYDROGENASE-C and -D are the primary genes involved in lignin biosynthesis in the floral stem of Arabidopsis. Plant Cell 17, 2059-2076 (2005).

54. Foster, C. E., Martin, T. M. \& Pauly, M. Comprehensive compositional analysis of plant cell walls (lignocellulosic biomass) Part II: carbohydrates. J. Vis. Exp. 37, e1837 (2010).

55. Gou, J. Y., Park, S., Yu, X. H., Miller, L. M. \& Liu, C. J. Compositional characterization and imaging of 'wall-bound' acylesters of Populus trichocarpa reveal differential accumulation of acyl molecules in normal and reactive woods. Planta 229, 15-24 (2008).

56. Olsson, A. M., Bjurhager, I., Gerber, L., Sundberg, B. \& Salmen, L. Ultra-structural organisation of cell wall polymers in normal and tension wood of aspen revealed by polarisation FTIR microspectroscopy. Planta 233, 1277-1286 (2011).

57. Stewart, J. J., Akiyama, T., Chapple, C., Ralph, J. \& Mansfield, S. D. The effects on lignin structure of overexpression of ferulate 5-hydroxylase in hybrid poplar. Plant Physiol. 150, 621-635 (2009).

58. Mansfield, S. D., Kim, H., Lu, F. \& Ralph, J. Whole plant cell wall characterization using solution-state 2D NMR. Nat. Protoc. 7, 1579-1589 (2012).

59. MacRae, E. in Protocols for Nucleic Acid Analysis by Nonradioactive Probes (eds Hilario, E. \& MacKay, J. F.) 15-24 (Humana Press, 2007).

60. Christensen, J. H., Bauw, G., Welinder, K. G., Van Montagu, M. \& Boerjan, W. Purification and characterization of peroxidases correlated with lignification in poplar xylem. Plant Physiol. 118, 125-135 (1998).

61. Pompon, D., Louerat, B., Bronine, A. \& Urban, P. Yeast expression of animal and plant P450s in optimized redox environments. Methods Enzymol. 272, 51-64 (1996).

62. Bhuiya, M. W. \& Liu, C. J. A cost-effective colorimetric assay for phenolic $O$-methyltransferases and characterization of caffeate 3-O-methyltransferases from Populus trichocarpa. Anal. Biochem. 384, 151-158 (2009).

63. Humphreys, J. M., Hemm, M. R. \& Chapple, C. New routes for lignin biosynthesis defined by biochemical characterization of recombinant ferulate 5-hydroxylase, a multifunctional cytochrome P450-dependent monooxygenase. Proc. Natl Acad. Sci. USA 96, 10045-10050 (1999).

64. Pettengill, E. A., Parmentier-Line, C. \& Coleman, G. D. Evaluation of qPCR reference genes in two genotypes of Populus for use in photoperiod and low-temperature studies. BMC Res. notes 5, 366 (2012).

65. Trapnell, C., Pachter, L. \& Salzberg, S. L. TopHat: discovering splice junctions with RNA-Seq. Bioinformatics 25, 1105-1111 (2009).

66. Langmead, B., Trapnell, C., Pop, M. \& Salzberg, S. L. Ultrafast and memoryefficient alignment of short DNA sequences to the human genome. Genome Biol. 10, R25 (2009).
67. Trapnell, C. et al. Transcript assembly and quantification by RNA-Seq reveals unannotated transcripts and isoform switching during cell differentiation. Nat. Biotechnol. 28, 511-515 (2010).

\section{Acknowledgements}

We thank Dr Paul J. Weimer (USDA, US Dairy Forage Research Center, Madison, WI) for kindly providing yeast fermentation strain D5A; and DuPont (Beloit, WI, USA) for their generous gift of Accellerase 1500. This work was supported by the Division of Chemical Sciences, Geosciences, and Biosciences, Office of Basic Energy Sciences of the U.S. Department of Energy (DOE BES) through Grant DEAC0298CH10886 to C.-J.L.; J.R. and H.K. were funded by the DOE Great Lakes Bioenergy Research Center (DOE BER Office of Science DE-FC02-07ER64494).

\section{Author contributions}

C.-J.L. designed and oversaw all of the studies, analysed and interpreted data, and wrote the manuscript. K.Z. designed and conducted aspen transformation, transgenic plant analyses, and cellulolytic measurement. Y.C. conducted cellulose content measurement, fermentation study, and enzyme activity inhibition assays. H.Y. maintained transgenic plants and conducted RNA-seq analysis. X.Z. characterized soluble phenolics. J.R. and H.K. performed NMR analyses and data interpretation. G.H. conducted scan electron microscopy study. M.L. assisted in synchrotron FT-IR imaging. All authors edited the manuscript.

\section{Additional information}

Supplementary Information accompanies this paper at http://www.nature.com/ naturecommunications

Competing financial interests: The authors declare no competing financial interests.

Reprints and permission information is available online at http://npg.nature.com/ reprintsandpermissions/

How to cite this article: Cai, Y. et al. Enhancing digestibility and ethanol yield of Populus wood via expression of an engineered monolignol 4-O-methyltransferase. Nat. Commun. 7:11989 doi: 10.1038/ncomms11989 (2016).

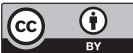

This work is licensed under a Creative Commons Attribution 4.0 International License. The images or other third party material in this article are included in the article's Creative Commons license, unless indicated otherwise in the credit line; if the material is not included under the Creative Commons license, users will need to obtain permission from the license holder to reproduce the material. To view a copy of this license, visit http://creativecommons.org/licenses/by/4.0/ 